\title{
LIMA MASÓNICA: LAS LOGIAS SIMBÓLICAS Y SU PROGRESO EN EL MEDIO URBANO A FINES DEL SIGLO XIX*
}

\author{
POR \\ MAGDALENA CHOCANO \\ Universitat Rovira i Virgili
}

Este artículo presenta un análisis de la organización de la Gran Logia del Perú, fundada en 1882. A partir de las fuentes masónicas, se busca establecer la dinámica de cada logia y el carácter del accionar masónico. Finalmente, se examinan las actitudes políticas que fomentaron sus dirigentes y su actuación en la escena nacional donde desafiaron al exclusivismo católico.

Palabras Clave: Liberales, masones, asociaciones, derechos ciudadanos, libertad religiosa.

Sabiduría que se remontaría a Moisés ${ }^{1}$ — si acatamos el hilo argumental de los discursos que los masones limeños pronunciaban en sus tenidas (sesiones) - y, a la vez, avanzada de modernidad y de progreso en una sociedad vivida como retrógrada y opresiva, la masonería que florecía a fines del siglo XIX en la capital de la república experimentó esta paradoja en todas sus empresas, tal como ocurría en otros ámbitos de los llamados - a fines del siglo XIX — «países latinos». La masonería ha sido objeto de diversos enfoques

* La autora agradece a la Gran Logia del Perú el permiso para consultar los materiales preservados en el Gran Museo y Archivo Histórico en Lima y, especialmente, las precisas orientaciones brindadas por su presidente, el R.. H. Francisco Sialer. Asimismo, agradece la atención recibida en la Biblioteca Pública Arús (Barcelona) y en la Sala de Revistas de la Biblioteca Nacional del Perú. Agradece, finalmente, los comentarios y preguntas de los asistentes a la conferencia ofrecida por la autora sobre el tema en el Instituto de Historia del CSIC que le han permitido perfilar con más claridad algunas cuestiones abordadas en este texto.

1 Villavicencio, «Institución Masónica», RMP, 107 (30 de septiembre de 1890): 198. 
académicos. Harland-Jacobs ha examinado el surgimiento y avance de la masonería británica como elemento en la construcción del sistema imperialista inglés ${ }^{2}$. Otros estudios, inspirándose en Weber, han apuntado a la cultura asociativa y sus valores a través de la pertenencia a las logias hallaron una expresión del «valor de crédito» atribuido a un individuo en sociedades de fuerte orientación comercial ${ }^{3}$. Los estudios sobre masonería francesa y española han explorado principalmente la inserción de la masonería en la conflictividad política de los siglos XIX y XX, y se han proyectado a las Antillas, en razón de haberse mantenido en éstas el poder colonial hasta $1898^{4}$. Aquí ofrecemos una descripción lo más orgánica posible de los datos compilados sobre la Gran Logia del Perú (GLP, de ahora en adelante), ya que muchos hechos y procesos de la historia de esta institución permanecen sin dilucidar desde el punto de vista académico, para apuntar algunas de las cuestiones sugeridas por los enfoque citados $^{5}$.

Los masones de la GLP buscaban fomentar las ideas liberales y contribuir a que arraigara una ciudadanía democrática fundada en los postulados de la Revolución Francesa. El origen presunto de la masonería peruana en el período de la independencia la vinculaba a los valores del republicanismo en lucha contra las opciones monárquicas favorecidas por algunos jefes de la lucha libertadora. Este legado era reivindicado por los masones peruanos en general, pero los masones que organizaron la GLP estimaron necesario subrayar su carácter de «masones ilustrados y liberales» ${ }^{6}$ que pugnaban por recuperar el carácter democrático de la masonería y se identificaban con una nueva generación que aspiraba a cumplir un papel regenerador en una sociedad que sufría las miserias de una posguerra tras la derrota ante Chile. En términos organizativos esto significaba que la GLP se convirtiera en el único cuerpo que rigiera a las logias simbólicas (que sólo trabajaban con tres grados: maestro, compañero y aprendiz), independizándolas de la jurisdicción del Supremo Consejo Grado 33, el cual llegó a ser visto por la GLP como un grupo despótico e inefectivo para cumplir con la misión de propagar los valores democráticos en la sociedad. La organización de la GLP se produjo en plena ocupación militar

2 Harland-Jacobs, 2006.

3 Beachy, 2000: 157-175.

4 Además de los numerosos trabajos de José Ferrer Benimeli, cabe mencionar: Sánchez Ferré, 1990, que ve en la masonería la última expresión del pensamiento tradicional europeo, y De Paz Sánchez, 2006, que explica el papel de la masonería en la independencia de Cuba y Puerto Rico.

5 Los textos más importantes de la historiografía masónica peruano son: López Albújar, 1958; Historia, 1982.

6 «La reforma», RM, 1 (15 de febrero de 1882): 2. 
chilena de Lima, y se propuso de modo explícito fomentar una masonería nacional que evitara que las logias constituidas en el país fueran regidas por grandes logias extranjeras. En este sentido, podemos decir que la GLP fue expresión de la nacionalización efectiva de la masonería en el Perú.

\section{La Gran Logia del Perú: LOGIAS, Membresía, FInANZAS}

No fue la GLP la primera potencia masónica que operaría en el Perú. Desde el siglo XIX existieron otras obediencias que habían pasado por diversas vicisitudes: el citado Supremo Consejo Grado 33 (fundado en 1830, refundado en 1848), la Gran Logia Provincial de Escocia (ciertas logias de la cual pasarían a la GLP en 1882), el Gran Oriente Peruano (sumido en un cisma en 1875). Hubo logias que se fundaron mediante cartas constitutivas otorgadas por grandes logias extranjeras, para evitar que el Supremo Consejo absorbiera todas las decisiones y recursos. Para tratar de minimizar la acción de estas nuevas logias, y asegurarse el control de la masonería nacional, el Supremo Consejo creó el Gran Oriente Peruano, pero por nuevas disensiones decidió extinguirlo en 1875, aunque sus miembros, encabezados por Arturo M. Wholey, siguieron reclamando dicho título. Al morir el Gran Comendador del Supremo Consejo, Antonio de Sousa Ferreira, en noviembre de 1881, fue elegido para este cargo, Francisco Javier Mariátegui (1793-1884), quien suspendió la expulsión perpetua del Gran Oriente, a la vez que desistía de la jurisdicción de las logias simbólicas y les ordenaba que se subordinaran a dicho Oriente ya nuevamente reconocido. Los miembros de las logias simbólicas se negaron a obedecer a un cuerpo formado por masones expulsados y no admitieron que el Supremo Consejo tuviera el derecho a transferir el gobierno de las logias a ninguna entidad ${ }^{7}$. Se sumó a este problema el que el Gran Oriente dirigido por Wholey había comenzado a iniciar a oficiales chilenos en la logia Orden y Libertad N. ${ }^{\circ} 1$, tal vez con la mira de facilitarles algún tipo de vida social en la capital, en cuyos salones no eran recibidos ${ }^{8}$.

Se produjo una «sublevación» masónica el 15 de diciembre de 1881, cuando Mariátegui, el nuevo Gran Comendador, quiso atajar la intervención del h. . Eduardo Lavergne, que cuestionaba la resolución emitida por el Gran Consejo, diciendo: «Los deltas [decretos] del Sup. $\therefore$ Cons. $\therefore$ del Perú se obedecen ciega-

7 Historia, 1982: 7 señala (basándose en el testimonio de Dam) que Juan Sánchez Silva, Gran Comendador interino del Consejo 33..$^{\circ}$, los planes para reinstaurar el Gran Oriente.

8 Solar (2000 [1886]: 125) señala que los oficiales chilenos no fueron invitados a los salones limeños durante los primeros meses de la ocupación. 
mente y no se discuten» ${ }^{9}$. La logia Virtud y Unión N.$^{\circ} 3$ presentó entonces el proyecto de establecer una Gran Logia que diera a las logias simbólicas su propio gobierno. El Supremo Consejo aceptó la propuesta, siempre y cuando no trabajasen con el rito escocés ${ }^{10}$. Así, el 25 de marzo de 1882, las logias Orden y Libertad N. ${ }^{\circ}$ 1, Orden y Libertad N. ${ }^{\circ} 2$, Virtud y Unión N. ${ }^{\circ} 3$, Parthenón N. ${ }^{\circ} 7$ y Alianza y Firmeza N. ${ }^{\circ} 16$ procedieron a fundar la Gran Logia del Perú ${ }^{11}$. Ese mismo año, las logias Honor y Progreso N. ${ }^{\circ} 479$, Cosmos N. ${ }^{\circ}$ 515, Arca de Noé N.$^{\circ} 521$ y Regeneración Fraternal N. ${ }^{\circ}$ 522, que hasta ahí habían estado bajo la obediencia de la Gran Logia Provincial de Escocia, decidieron adherirse a la GLP, para lo cual cambiaron de numeral ${ }^{12}$. Su primer Gran Maestre fue el Dr. Antonio Arenas (1808-1891).

Cada logia requería un mínimo de seis hombres (no se preveía el caso de mujeres que desearan iniciarse), y entre ellos debía elegirse a los oficiales del «cuadro» o cuerpo directivo de la logia: Venerable Maestro, Past Maestro, $1 .^{\circ}$ y 2..$^{\circ}$ Vigilantes, Gran Tesorero, Gran Secretario, etc. Un «cuadro» análogo dirigía la GLP, si bien los cargos supremos recibían el título de Gran Maestre y Past Gran Maestre. Hacia 1890 la GLP llegó a tener bajo su jurisdicción 26 logias (véase cuadro), y posteriormente sumaría las 31 logias que figuran en el mapa, donde podemos apreciar la alta concentración de logias existente en Lima, aunque había un número significativo en ciudades de otros departamentos e incluso fuera de las fronteras del país. Fuera de una cotización mensual, los hermanos masones debían contemplar otros desembolsos: la promoción de grado requería un mínimo de 10 soles (para aprendiz y maestro) y de 5 soles (para compañero). La impresión de reglamentos y «procedimientos» (calco del inglés proceedings, actas) requería el pago de cuotas extraordinarias: así, por ejemplo, cada logia debió aportar 20 soles para la impresión de las actas o procedimientos de 1888 y $1889^{13}$. Las logias reclutaban a sus miembros en el

9 «Memoria del Ven. M. de la logia Orden y Libertad N. ${ }^{\circ} 2 \ldots », R M, 14$ (1. ${ }^{\circ}$ de enero de 1883): 12. También «Christian Dam», El libre pensamiento, 35 (30 de enero de 1897): 141.

10 «Manifiesto a las Grandes Logias y Cuerpos Supremos de todos los Ritos reconocidos de la Francmasonería», $R M, 12$ (1. ${ }^{\circ}$ de noviembre de 1882): 50-53. La lucha jurisdiccional se había ya iniciado en 1859 en los «países latinos», con el fin de persuadir a los supremos consejos de que cesaran en sus intentos de tener jurisdicción sobre los grados simbólicos o azules. («Comentarios del h. A Albert Pike», 106 [31 de agosto de 1890]: 177-178). Albert Pike (1809-1891), nació en Boston, fue abogado y militar del ejército confederado del sur, escribió Morals and Dogma of the Ancient and Accepted Scottish Rite of Freemasonry (Charleston, 1871).

11 López Albújar, 1958: 71.

12 Reseña histórica, 2005. Pero las logias del Callao pertenecientes a la Gran Logia Provincial no se incorporaron.

13 «Crónica», RMP, 107 (30 de septiembre de 1890): 196. 


\begin{tabular}{|c|c|c|c|c|c|c|c|c|c|c|c|c|c|c|c|c|}
\hline 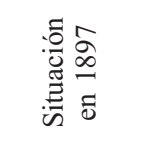 & 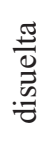 & $\begin{array}{l}0 \\
\stackrel{0}{0} \\
\stackrel{0}{0} \\
\overline{0}\end{array}$ & : & : & . & . & : & $\cdot \stackrel{\Xi}{0}$ & : & 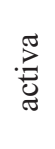 & 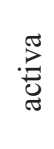 & $\cdot \stackrel{\pi}{0}$ & : & : & 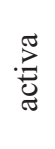 & 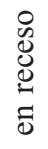 \\
\hline 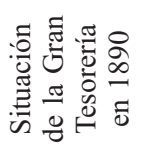 & $\underset{\dot{\phi}}{\dot{\phi}}$ & 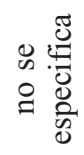 & 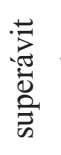 & 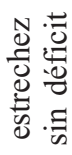 & 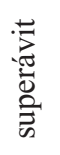 & $\dot{\dot{m}}$ & 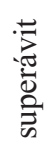 & 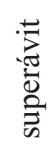 & 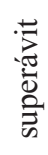 & $\overrightarrow{\dot{D}}$ & $\underset{\dot{m}}{\vec{D}}$ & $\overrightarrow{\dot{m}}$ & $\begin{array}{l}\frac{\pi}{7} \\
\stackrel{0}{0} \\
0 \\
0 \\
0\end{array}$ & $\dot{\vec{s}}$ & $\overrightarrow{\dot{m}}$ & $\overrightarrow{\dot{D}}$ \\
\hline 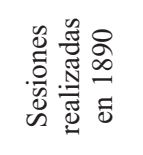 & $\underset{\dot{m}}{\dot{m}}$ & 8 & $\approx$ & $\ddot{\dot{\omega}}$ & $\tilde{6}$ & $\ddot{\sim}$ & & $\curvearrowright$ & ले & $\begin{array}{l}0 \\
0 \\
0 \\
0 \\
0 \\
\tilde{0}\end{array}$ & in & 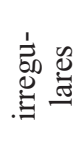 & 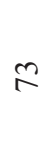 & 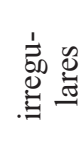 & $\begin{array}{l}0 \\
0 \\
0 \\
0 \\
0 \\
\tilde{0}\end{array}$ & ن. \\
\hline 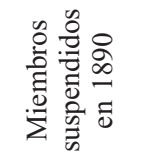 & $\underset{\dot{m}}{\dot{d}}$ & | & $\overrightarrow{\dot{D}}$ & வ் & 6 & $=$ & $\underset{\dot{\phi}}{\dot{D}}$ & $\tilde{m}$ & $\underset{\dot{D}}{\dot{D}}$ & $\overrightarrow{\dot{D}}$ & $\infty$ & $\underset{\dot{\phi}}{\dot{\phi}}$ & $\Xi$ & $\underset{\dot{m}}{\dot{D}}$ & $\vec{r}$ & $\underset{\dot{\phi}}{\dot{D}}$ \\
\hline 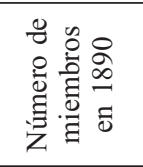 & $\underset{\dot{\phi}}{\dot{D}}$ & $\bar{\sim}$ & $\underset{\dot{\phi}}{\dot{\phi}}$ & ટ் & $\bar{n}$ & $\approx$ & $\underset{\dot{\phi}}{\dot{D}}$ & $\stackrel{P}{r}$ & $\underset{\dot{\omega}}{\dot{D}}$ & $\overrightarrow{\dot{n}}$ & $\mathscr{f}$ & $\underset{\dot{\phi}}{\dot{\phi}}$ & b & $\overrightarrow{\dot{D}}$ & $\overrightarrow{\dot{D}}$ & $\underset{\dot{\phi}}{\dot{\phi}}$ \\
\hline 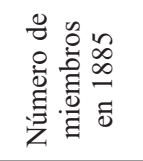 & $\infty$ & $n$ & $\underline{n}$ & $\hat{n}$ & $\stackrel{\infty}{\sim}$ & ల & そ & $\stackrel{\infty}{\sigma}$ & in & $\simeq$ & in & t & ? & $\stackrel{\infty}{m}$ & શి & $\bar{n}$ \\
\hline 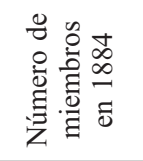 & $\infty$ & $\stackrel{\infty}{+}$ & ป & $\hat{n}$ & 2 & 宓 & $\bar{n}$ & ஓ & $\bar{n}$ & $\simeq$ & in & in & $\stackrel{n}{f}$ & $a$ & m & $\mid$ \\
\hline 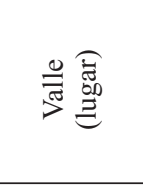 & 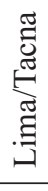 & $\stackrel{\overparen{G}}{\Xi}$ & $\stackrel{\widetilde{\Xi}}{\Xi}$ & $\stackrel{\overparen{\Xi}}{\leftrightarrows}$ & 芚 & $\stackrel{\mathbb{\Xi}}{\Xi}$ & $\stackrel{\Xi}{\Xi}$ & $\stackrel{\widetilde{g}}{\exists}$ & $\stackrel{\widetilde{J}}{.}$ & 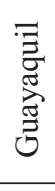 & 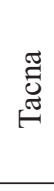 & $\frac{8}{\bar{\Xi}}$ & 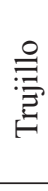 & $\begin{array}{l}\tilde{\sigma}_{0} \\
\tilde{e}_{0} \\
\vec{\Xi} \\
\stackrel{\Xi}{\Sigma}\end{array}$ & 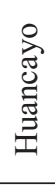 & 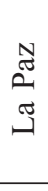 \\
\hline $\begin{array}{l}. \frac{\pi}{60} \\
0 \\
0\end{array}$ & 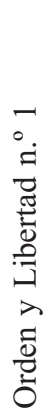 & 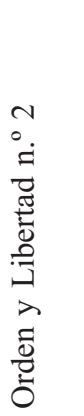 & 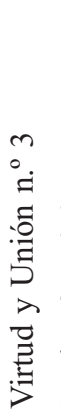 & 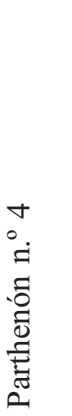 & $\begin{array}{l}n \\
0 \\
\dot{I} \\
0 \\
0 \\
0 \\
0 \\
0 \\
0 \\
0 \\
\lambda \\
\lambda \\
\overrightarrow{0} \\
0 \\
0 \\
0\end{array}$ & 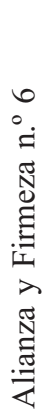 & $\begin{array}{l}n \\
0 \\
\dot{D} \\
0 \\
0 \\
\text { E. } \\
0 \\
0\end{array}$ & 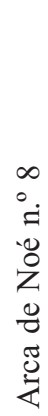 & 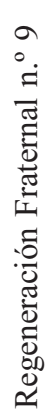 & 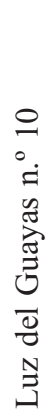 & 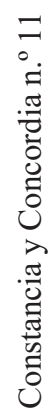 & 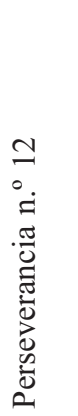 & 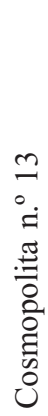 & 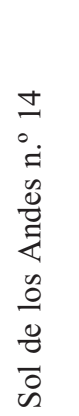 & 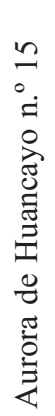 & $\begin{array}{l}0 \\
0 \\
0 \\
\dot{0} \\
. \\
0 \\
0 \\
0 \\
0 \\
0 \\
0 \\
0 \\
0 \\
0 \\
0 \\
0 \\
0 \\
0 \\
0\end{array}$ \\
\hline
\end{tabular}




\begin{tabular}{|c|c|c|c|c|c|c|c|c|c|c|}
\hline 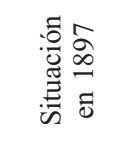 & $\begin{array}{l}0 \\
0 \\
0 \\
0 \\
0 \\
0\end{array}$ & 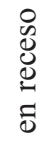 & 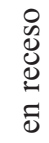 & : & $\begin{array}{l}0 \\
0 \\
0 \\
0 \\
0 \\
\overline{0}\end{array}$ & 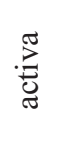 & $\stackrel{己}{\tilde{d}}^{\pi}$ & . & $\begin{array}{l}0 \\
0 \\
0 \\
0 \\
0 \\
\tilde{0}\end{array}$ & $\begin{array}{l}0 \\
0 \\
0 \\
0 \\
0 \\
0 \\
0\end{array}$ \\
\hline 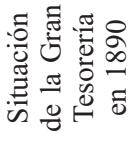 & $\underset{\dot{\varphi}}{\dot{D}}$ & $\underset{\dot{\phi}}{\dot{\phi}}$ & $\overrightarrow{\dot{\phi}}$ & 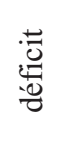 & $\dot{\dot{m}}$ & 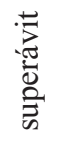 & $\underset{\dot{m}}{\dot{d}}$ & $\underset{\dot{m}}{\dot{D}}$ & $\underset{\dot{m}}{\dot{D}}$ & $\overrightarrow{\dot{m}}$ \\
\hline 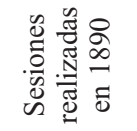 & 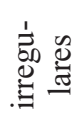 & $\underset{\dot{\phi}}{\dot{\phi}}$ & $\underset{\dot{m}}{\dot{m}}$ & $\bar{n}$ & $\underset{\dot{m}}{\vec{\phi}}$ & $\bar{n}$ & $\overrightarrow{\dot{s}}$ & $\underset{\dot{m}}{\dot{m}}$ & $\overrightarrow{\dot{n}}$ & $\underset{\dot{\phi}}{\dot{\phi}}$ \\
\hline 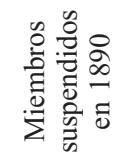 & $\underset{\dot{\infty}}{\dot{D}}$ & $\underset{\dot{\infty}}{\dot{D}}$ & $\overrightarrow{\dot{\theta}}$ & - & $\underset{\dot{s}}{\dot{s}}$ & $\underset{\dot{\omega}}{\dot{m}}$ & $\overrightarrow{\dot{s}}$ & $\underset{\dot{\omega}}{\dot{D}}$ & $\overrightarrow{\dot{n}}$ & $\underset{\dot{\omega}}{\dot{s}}$ \\
\hline 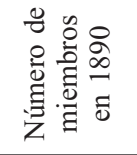 & $\underset{\dot{\varphi}}{\dot{D}}$ & $\underset{\dot{m}}{\dot{m}}$ & $\underset{\dot{m}}{\dot{m}}$ & $\dot{\ddot{D}}$ & $\overrightarrow{\dot{n}}$ & 导 & $\underset{\dot{m}}{\dot{m}}$ & $\underset{\dot{m}}{\dot{D}}$ & $\dot{\vec{n}}$ & $\begin{array}{l}\dot{\vec{s}} \\
\dot{\boldsymbol{s}}\end{array}$ \\
\hline 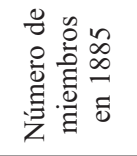 & $\stackrel{\infty}{\sim}$ & $\tilde{n}$ & $\bar{n}$ & $\dot{d}$ & $\underset{\dot{s}}{\dot{m}}$ & $\underset{\dot{m}}{\dot{m}}$ & $\overrightarrow{\dot{s}}$ & $\underset{\dot{m}}{\dot{D}}$ & $\overrightarrow{\dot{n}}$ & $\overrightarrow{\dot{m}}$ \\
\hline 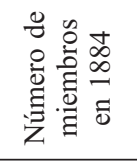 & $\mid$ & 1 & 1 & $\dot{\dot{D}}$ & $\underset{\dot{s}}{\dot{m}}$ & $\underset{\dot{\phi}}{\dot{D}}$ & $\underset{\dot{m}}{\dot{m}}$ & $\underset{\dot{m}}{\dot{D}}$ & $\underset{\dot{m}}{\dot{D}}$ & $\overrightarrow{\dot{n}}$ \\
\hline 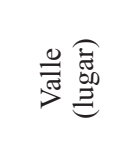 & 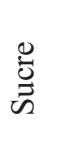 & 일 & $\frac{\sqrt{\pi}}{\stackrel{\pi}{\pi}}$ & $\cdot \stackrel{\Xi}{Z}$ & $\frac{\frac{8}{0}}{\frac{0}{0}}$ & $\begin{array}{ll}8 & 8 \\
0 & 0 \\
0 & 0 \\
0 & 0\end{array}$ & 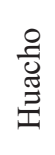 & 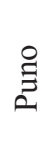 & 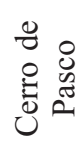 & $\begin{array}{c}\sqrt{\pi} \\
\tilde{\pi} \\
\pi\end{array}$ \\
\hline $\begin{array}{l}\text {. } \\
.05 \\
0 \\
\end{array}$ & 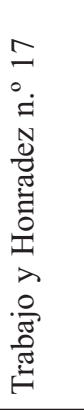 & 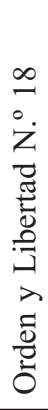 & 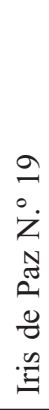 & 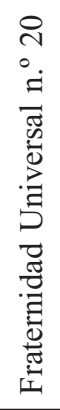 & 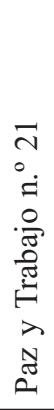 & 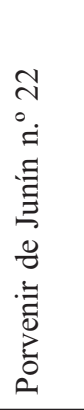 & 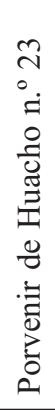 & 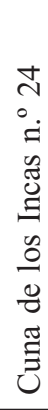 & 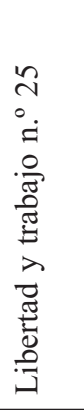 & 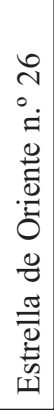 \\
\hline
\end{tabular}

Revista de Indias, 2010, vol. LXX, n. ${ }^{\circ}$ 249, 409-444, ISSN: 0034-8341 doi:10.3989/revindias.2010.013 


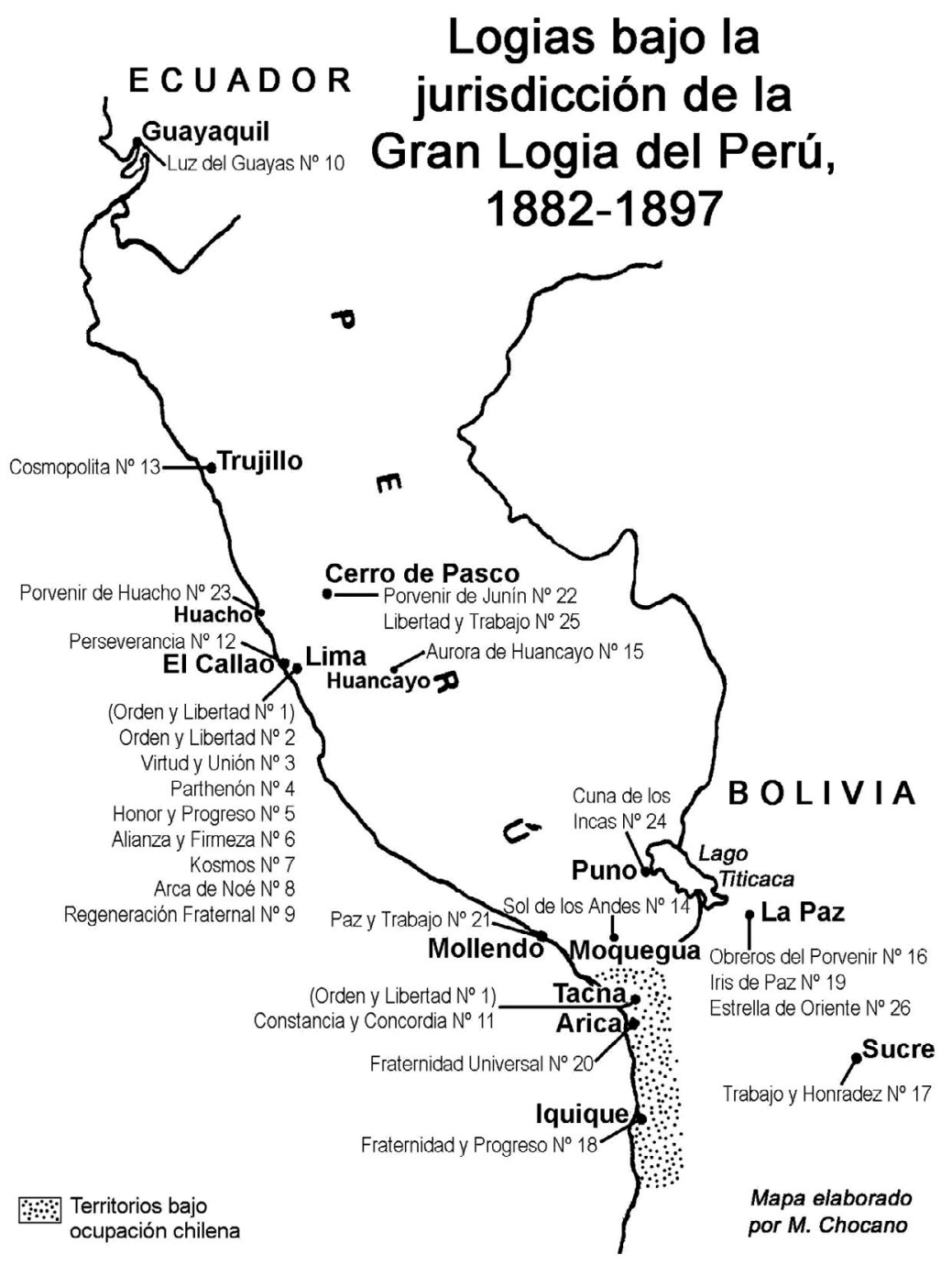

segmento profesional burgués: abogados, médicos, militares, empleados particulares y públicos, jurisconsultos, propietarios, comerciantes ${ }^{14}$. Eran hom-

14 Una muestra de solicitudes de admisión a las logias 1, 3, 5, 4, 8 y 61 permite constatar el alto porcentaje de comerciantes que las suscribían: 61 de un total de 134, mientras que apenas se consignan unos cuatro o cinco individuos que podamos contar como artesanos (Valdivia Acuña, 2002: 189-195). Una lista de los integrantes del cuadro directivo de la logia Alianza y 
bres con autonomía económica, con un nivel superior de educación o por lo menos con aspiraciones claras de instruirse y de mejorar su nivel educativo, y que podían plantearse el solventar su membresía. No tenemos indicios de logias formadas por artesanos u otros trabajadores manuales, aunque en la instalación de la GLP se hallaron presentes representantes de todas las profesiones y nacionalidades, de la ciencia, la industria y el trabajo, desde modestos artesanos hasta acaudalados propietarios ${ }^{15}$. En cuanto a las mujeres, su exclusión de las logias se daba por sentada, sin que esto fuera óbice a que los masones manifestaran una constante preocupación por la educación femenina.

Los datos tomados de las memorias anuales publicadas permiten que nos hagamos una idea general de la actividad y membresía de las logias. Lo más destacado del cuadro es la disminución en la membresía que se aprecia entre 1886 y 1890 . Es posible que una exigencia más estricta del pago de la cotización mensual tuviera un efecto depurador. La GLP registra para el año 1885 ingresos más abultados por diplomas, la compra de cartas constitutivas o las contribuciones para la impresión de documentos ${ }^{16}$, pero siendo la cotización la base de la economía asociativa, su exigencia puede haber moderado el interés participativo de miembros que por alguna razón no se planteaban asumir este gasto regularmente.

La estadística masónica general a veces no es congruente con los datos que aparecen en las memorias de cada logia, puesto que las logias pasaban por situaciones diversas. Como se ha dicho, la logia Orden y Libertad N. ${ }^{\circ} 1$ se organizó en Lima con militares chilenos de las fuerzas ocupantes de la capital, y posteriormente pasó a regularizar su obediencia a la GLP. En 1884 era la segunda en número de miembros (véase cuadro), pero en julio de ese año se autorizó su traslado a Tacna como consecuencia de la retirada de las tropas chilenas. Sin embargo, su actividad cesó ya en 1886 hasta que fue disuelta en $1887^{17}$. De modo que las logias limeñas realmente activas serían sólo ocho, comenzando por la Orden y Libertad N. ${ }^{\circ}$ 2, que, aunque no era la más numerosa,

Firmeza N. ${ }^{\circ} 16$ de 1874 indica las siguientes profesiones: 2 ingenieros, un arquitecto, dos abogados, un militar, dos propietarios rurales, seis empleados, siete comerciantes y 1 negociante (Gran Archivo y Museo Masónico de la GLP, exposición).

15 Reseña histórica, 2005.

16 Procedimientos, 1887: 75.

17 Véase Romo Sánchez, 2005a: 48, donde además se desmiente la calidad de masón del almirante Patricio Lynch, jefe de las fuerzas de ocupación chilenas en Lima. Esta logia debió ser regularizada ante la GLP pero, de algún modo, se puede considerar como un intento de incorporar a ciertos elementos liberales de las fuerzas de ocupación a la sociabilidad liberal limeña, aunque se consideró que fueron llamados sólo para lograr el traspaso del local del templo masónico sito en Callejón de San Francisco, 27: Historia, 1982: 9. 
era considerada como la más antigua de la jurisdicción y sus miembros se preciaban de que no hubiera abatido jamás sus columnas (es decir, cesado su actividad) desde el presunto año de su fundación en $1822^{18}$. Los 21 miembros de 1890 eran todos cotizantes, sin embargo, sólo 12 asistían habitualmente en las sesiones de la logia, e incluso se menciona que alguna se hubo de suspender por falta de quórum. De todos modos, estos doce miembros sí se preocuparon por mantener activa la logia. Se enorgullecían en especial de que dos de ellos cultivaran la columna de armonía (música), lo cual nos insinúa un aspecto importante para la sociabilidad masónica ${ }^{19}$. En 1891 esta logia realizó 48 tenidas; aunque la asistencia de los hermanos bajó a diez por sesión, se atribuyó esta deficiencia a varias razones: la refacción del templo, una epidemia de influenza en el verano, las elecciones presidenciales de 1890. En 1891 la logia llegaba a 22 miembros, pero su economía no mostraba signos de mejora: debía 464,0 soles por las refacciones del templo, y debía aportar 100 soles para construir un obelisco en honor de los caídos en la guerra con Chile, tal como lo había propuesto la logia Honor y Progreso N. ${ }^{0}{ }^{20}$.

La logia Virtud y Unión N. ${ }^{\circ} 3$ era la más numerosa de la jurisdicción en 1884 con 122 miembros, y en 1890 realizaría 65 sesiones. De todos modos, el Venerable Maestro se lamentaba de que la asistencia hubiera sido escasa, lo que se habría debido, «a ser muchos de ellos empleados públicos, cuyas labores no están limitadas». Esta logia por tanto queda identificada con un sector social específico. Con un superávit de más de 300 soles de plata $^{21}$, sus finanzas presentan un aspecto más saneado que las de la logia N. ${ }^{\circ} 2$. A la logia Parthenón $\mathrm{N}^{\circ} 4$ se le asigna como fecha de fundación $1825^{22}$. Sólo hay noticias del número de sus miembros para 1884 y 1885: 57; para 1890 no hay datos. En dicho año, Augusto Angulo, el Venerable Maestro de esta logia, afirmaba que la marcha regular del taller era muy dificultosa. Las sesiones se convocaban, pero los hermanos no acudían con puntualidad, lo cual atribuía «al malestar general del país». Algunos miembros ya aceptados no mostraron ser buenos masones, mientras otros, incluso habiendo sido aceptados, no se presentaron a la iniciación. La economía de esta logia atravesaba dificultades por las reduci-

18 «Memoria anual de la R. . L. O Orden y Libertad N. ${ }^{\circ}$ 2», RMP, 109-110 (noviembre-diciembre de 1890): 241.

19 «Memoria Anual de la R. $\cdot$ L. $\therefore$ Orden y Libertad N. ${ }^{\circ} 2 »$, ibid.: 85.

20 «Memoria anual de la R. . L. Orden y Libertad N. ${ }^{\circ} 2 »$, ibid.: 241.

21 «Memoria leída por el V. . M.. Paul Ascher...», ibid.: 245.

22 Torres Chávez, 2006, atribuye su fundación al general colombiano Manuel Antonio Valero, con el número y con el nombre de Orden y Reforma N. ${ }^{\circ}$, correspondiente al rol de las logias neogranadinas. Después habría entrado en un largo receso y en 1875 los asociados del momento decidieron cambiar su denominación a Parthenón N. ${ }^{\circ} 4$. 
das entradas registradas en la caja, pese a haber logrado hacer contribuciones para la confección de medallas y demás útiles masónicos, y estar comprometida a pagar la parte que le correspondía por la refacción del templo ${ }^{23}$.

En cambio, la logia Honor y Progreso N. ${ }^{\circ} 5$ (fundada en $1868^{24}$ ) contaba con 76 miembros en 1884, y en 1890 atravesaba un período de gran actividad y crecimiento pues casi duplicaba este número al registrar 151 miembros activos y 43 honorarios. Formaban parte de la logia personas que se distinguían por su activismo político y social: José Fernando Gazzani, que sería ministro; Alberto Químper, abogado del predicador protestante Francisco L. Penzotti; José Payán, financista cubano radicado en el Perú. En 1890 la logia realizó 65 sesiones y organizó una velada por Fiestas Patrias muy elegante a la que asistieron «caballeros profanos» (es decir, hombres no iniciados en la masonería) y «52 señoras y señoritas de la culta sociedad de Lima» ${ }^{25}$. La economía de la logia estaba saneada, y en su interior se había organizado una «Sociedad de Protección de Auxilios» integrada por 34 hermanos masones con su propia contabilidad, cuyos fondos estaban en parte depositados en una cuenta del Banco del Callao, cuyo gerente era José Payán, miembro de la logia.

La logia Alianza y Firmeza N. ${ }^{\circ}$ 6, en pronunciado contraste con la anterior, refleja más bien un clima de pesimismo, comprensible dado que su evolución demuestra una tendencia clara a la disminución. En 1882 consiguió nuevos adeptos al rebajar el 50 por 100 de la cotización a los estudiantes universitarios, quienes realizaron debates sobre temas filosóficos, sociales y morales para «levantar el espíritu del pueblo», aunque con éxito limitado ${ }^{26}$. En 1884 tenía 54 miembros, pero en 1890 contaba sólo con 25 hermanos, habiendo sido 26 el año anterior. Además, el Venerable Maestro, Federico Ego-Aguirre, estaba aquejado de una enfermedad que le impedía realizar más sesiones (sólo se hicieron 27 en 1890, frente a 57 en 1889). Ego-Aguirre, sin embargo, consideraba que la mayor causa de la decadencia de esta logia era efecto del desánimo existente que afectaba también a los masones: «el abatimiento imponderable del espíritu público, casi por sí solo produce el estacionarismo masónico alejando del seno de las Logias todas aquellas fuerzas que pudieran moverlas y levantarlas...». Enfatizaba que la causa de esta desidia era que no se permitía tratar de política y religión en

23 «Memoria del Venerable Maestro de la Respetable Logia Partenón N.o 4», RMP, 115 (31 de mayo de 1891): 109.

24 Estuvo adscrita con el N. ${ }^{\circ} 479$ en el rol universal en la Gran Logia de Escocia. Una medalla indica una fundación aún más antigua: 1858 (Reseña histórica, 2005).

25 «Informe leído por el h. Bernabé Gonzalo de la Torre, secretario...», RMP, 109-110 (noviembre-diciembre de 1890): 249.

26 «Crónica», $R M, 3$ (15 de marzo de 1882): 18. 
las logias ${ }^{27}$. En efecto, las normas vigentes en la francmasonería anglosajona prohibían que se hablara de política y de religión pues así se evitaba el conflicto entre hombres de diversas religiones y simpatías políticas. Pero en el contexto peruano, el acatamiento de esta regulación esterilizaba la sociabilidad masónica, por lo menos desde el punto de vista del Venerable de la logia $\mathrm{N}^{\circ}{ }^{\circ} 6, \mathrm{y}$, como veremos, no se cumplió con dicha regulación.

La logia Kosmos N. ${ }^{\circ} 7$ realizaba sus trabajos en inglés, es de suponer por tanto que sus miembros eran ingleses y/o estadounidenses radicados en el país. Fue una de las que pidió su incorporación a la Gran Logia del Perú en 1882. Era una logia rica, en 1890 tenía un superávit de más de 400 soles de plata. Sin embargo, tenía problemas para seguir funcionando como tal. El venerable maestro, Francisco L. Crosby, decía que tenía 29 miembros activos, pero que en realidad sólo ocho asistían a las sesiones pues el resto residía fuera de Lima. Los que vivían en el Callao no podían asistir porque había cambiado el horario de los trenes, pero el problema principal era la desidia de los hermanos de esta logia, lamentada por Crosby: «Nuestra logia es la única de habla inglesa en Lima y por orgullo, a falta de más digno motivo, deberíamos sentirnos obligados a sostenerla y no dejar que se diga en las calles y plazas del mundo masónico que la colonia de habla inglesa de Lima es demasiado pobre de espíritu para sostener su Logia». Esta logia funcionaba en un local de la calle Negreiros, y parece haber sufrido ciertos actos de hostilidad por parte del vecindario ${ }^{28}$.

La logia Arca de Noé N. ${ }^{\circ} 8$ presenta una historia accidentada. Había surgido en 1872 con el número 521, dependiente de la Gran Logia de Escocia, pero tras unos años de actividad «abatió sus columnas» en 1877. Según la constitución de la Gran Logia de Escocia, una logia que dejara de existir por más de cuatro años, perdía su carta constitutiva; para evitarlo, once hermanos de otras logias decidieron reinstalarla. Poco tiempo después, en 1882, se adhirieron a la GLP. Aunque el número de sus miembros disminuyó de 98 en 1885 a 80 en 1891, se trataba de hermanos que cotizaban puntualmente y se enorgullecían de su crédito inmaculado ${ }^{29}$. Las noticias de la logia Regeneración Fraternal N. ${ }^{\circ} 9$ son imprecisas para 1890; sin embargo, las referencias a iniciaciones y

27 «Memoria del Venerable Maestro de la Resp. $\therefore$ Logia Alianza y Firmeza N. ${ }^{\circ} 6$ correspondiente al año 1890», RMP, 114 (30 de abril de 1891): 82-84.

28 «Memoria anual del Ven.. Maest.. de la R. $\therefore$ L. Kosmos N. ${ }^{\circ} 7$ (traducción)», RMP, 109-110 (noviembre-diciembre de 1890): 254 y 275. Se denuncia un amago de incendio y un intento de intrusión. F. L. Crosby era «representante de las fábricas norteamericanas para la importación» (véase aviso en El libre pensamiento, 13 [29 de agosto de 1896]: 51).

29 M. J. Cáceres, «Anales de la logia Arca de Noé en sus dos épocas», RMP, 114 (30 abril de 1891): 97-98. 
promociones indican que en esa fecha contaba con unos 20 hermanos, lo cual sugiere una fuerte disminución ya que en 1885 había llegado a tener 56 miembros. Su situación económica, no obstante, era buena.

En síntesis, las logias limeñas, aun con contratiempos y dificultades, mantuvieron una actividad constante en estos años de la posguerra, formando por tanto el núcleo más fuerte de la GLP. En cambio, en el vecino puerto del Callao la GLP no tuvo tanta facilidad para implantar su jurisdicción, pues las varias logias que existían allí siguieron obedeciendo a «orientes» foráneos ${ }^{30}$. En 1889 se consiguió instalar una logia haciendo uso de la carta constitutiva de la antigua logia Perseverancia N. ${ }^{\circ} 12$, que había existido en Lima, pero que «había abatido sus columnas». La fundación de la nueva edición de esta logia sufrió algunos tropiezos, incluso privaciones materiales como la falta de local, pues no pudieron llegar a un acuerdo inmediato con las demás logias chalacas para hacer uso del mismo local. De todos modos, la instalación se realizó.

En Trujillo se había reconstruido la logia Cosmopolita N..$^{\circ} 13$, y se dan noticias de una membresía de 50 hermanos, aunque catorce no cumplían con pagar la cotización, razón por la que habían sido suspendidos. José M. Laines Lozada, gran secretario de la logia, lamentaba que, entre esos catorce, hubiera personas con fortuna más que sobrada para satisfacer dicha obligación y no lo hicieran ${ }^{31}$. Informaba que se habían realizado 73 sesiones, pero decía que en sus ocho años de existencia, la logia no había avanzado mucho debido a las calumnias de los «hipócritas fanáticos» y recomendaba una actitud selectiva en la admisión de profanos. Estos obstáculos se veían compensados por la generosidad y entusiasmo de otros miembros de la logia: el hermano Pablo Rojas compró tres malletes (símbolo del grado de maestro) que obsequió a tres oficiales de la orden ${ }^{32}$. Más optimistas eran las apreciaciones del Venerable Maestro, José B. Goicochea, quien aseguraba que la propaganda del «liberalismo racional y justiciero» se extendía, disipando «la ignorancia y el fanatismo» del pueblo ${ }^{33}$.

Los informes de otras logias provincianas, sin embargo, son menos alentadores. La logia moqueguana Sol de los Andes N. ${ }^{\circ} 14$ había llegado a tener 38 miembros en 1885, pero en 1890 su actividad era esporádica (véase cuadro). La Aurora de Huancayo N. ${ }^{\circ} 15$, presenta una situación análoga: en receso en 1890, había llegado a tener 33 miembros en 1884. De la llamada Libertad y

30 «Memoria de la R.. L. Perseverancia N. ${ }^{\circ}$ 12», RMP, 99 (31 de enero de 1890): 14-18.

31 «Memoria presentada a la R. . Logia Cosmopolita n. ${ }^{\circ} 13$ por el V. Maestro H. . José M. Laines Lozada», RMP, 99 (31 de enero de 1890): 18.

32 «R. L Logia Cosmopolita n. ${ }^{\circ} 13 », R M P, 100$ (28 de febrero de 1890): 42-44.

33 «Noticias de Trujillo», RMP, 99 (31 de enero de 1890): 2. 
Trabajo N..$^{\circ} 25$ (Cerro de Pasco) no hay información. En la misma región más activa se manifestó la logia Porvenir de Junín N. ${ }^{\circ} 22$, que realizó 31 sesiones y tenía una membresía de 14 hermanos presumiblemente y sus finanzas saneadas. Lo mismo se puede decir de la logia Porvenir de Huacho N. ${ }^{\circ} 23$, pues hizo un donativo para la construcción de un hospital en esa localidad ${ }^{34}$, aunque no tenemos datos del número de sus miembros. En el sur del país, de la logia puneña Cuna de los Incas N. ${ }^{\circ} 24$ y de la mollendina Paz y Trabajo N..$^{\circ} 21$, sólo conocemos la lista de oficiales electos para 1890. Aunque no puede decirse que por lo menos los miembros de esta última estuvieran inactivos, pues en abril de 1893 su templo masónico fue atacado por una turba católica, cuando velaban los restos de Emilio Cazorla, su antiguo venerable ${ }^{35}$.

Una situación especial presentaban las logias en los territorios ocupados por Chile a raíz de la guerra. Ya hemos mencionado la disolución de la Orden y Libertad N. ${ }^{\circ} 1$ tras su traslado a Tacna, donde la logia Constancia y Concordia $\mathrm{N}^{\circ}{ }^{\circ} 11$, pese a todo, se mantuvo activa: ocho nuevos miembros ingresan en 1889. En 1890 celebró 58 sesiones con una asistencia promedio de 18 hermanos. Aunque el número de sus miembros era 45, sólo 34 eran miembros activos, pues tenía un miembro honorario, ocho suspendidos (quizá por no pagar la cotización) y dos enjuiciados ${ }^{36}$. La actividad de la logia $\mathrm{N}$. $^{0} 11$ contrasta con la precariedad de la logia ariqueña Fraternidad Universal N. ${ }^{\circ}$ 20, debido a su mala situación económica y la falta de reconocimiento legal. Fue fundada en 1886 con carta constitutiva de la GLP ${ }^{37}$. En agosto de 1890 lograron consagrar su templo, en una ceremonia a la que concurrieron los masones de Tacna ${ }^{38}$. Durante un tiempo impulsaron la celebración de las Fiestas Patrias bajo la ocupación hasta su prohibición por la autoridad chilena en julio de $1900^{39}$. También experimentaron muy directamente la hostilidad eclesiástica: el cura de la parroquia se negó a bendecir el matrimonio de uno de los miembros de la logia por ser masón ${ }^{40}$. Mientras en Tacna la logia N. ${ }^{\circ} 11$ se mantuvo con una relativa fortaleza, en Arica la logia N.$^{\circ} 20$ tropezó con graves dificultades, y parece también haber tenido diferencias con la logia Morro de Arica obediente

34 «Logia Porvenir de Huacho N. . 23», RMP, 109-110 (junio-julio de 1890): 277.

35 Armas Asín, 2000: 171. Valdivia Acuña, 2002: 106.

36 «Informe del Secretario de la R. . Logia Constancia y Concordia N. ${ }^{\circ} 11 », R M P, 99$ (31 de enero de 1890): 9.

37 Romo Sánchez, 2005b: 11-25.

38 «Arica», RMP, 106 (31 de agosto de 1890): 169.

39 Romo Sánchez, 2006: 24-25.

40 «Memoria anual de la logia Fraternidad Universal N. ${ }^{\circ} 20$ de Arica», RMP, 102 (30 de abril de 1890): 82-83. 
al Supremo Consejo del Grado 3341. No sabemos cuándo Fraternidad y Progreso N. ${ }^{\circ} 28$, fundada en Iquique en 1875 , se incorporó a la GLP, pero logró mantenerse activa hasta 1919 por lo menos, en que se vio compelida a abandonar la ciudad debido a la violenta chilenización que soportó la población peruana de la provincia de Tarapacá ${ }^{42}$.

No hay datos suficientes sobre la procedencia de la membresía de las logias fundadas en el extranjero adscritas a la GLP. Podría pensarse que sus fundadores eran peruanos exiliados de las contiendas civiles. Para la logia Luz del Guayas N. ${ }^{\circ} 10$, en Guayaquil, las noticias de 1884 y 1885 indican una membresía de 12 hermanos, pero en 1890 ya se hallaba en receso. Las logias situadas en Bolivia fueron relativamente numerosas: Obreros del Porvenir N. ${ }^{\circ} 16$ (La Paz), que fue fundada en 1884 por el diplomático boliviano Zoilo Flores, con 51 miembros cada una en 1885. Sobre Iris de Paz N. ${ }^{\circ} 19$ y Estrella de Oriente N. ${ }^{\circ} 26$ de La Paz carecemos de datos para todo el período, y casi lo mismo ocurre con Trabajo y Honradez N. ${ }^{\circ} 17$ (Sucre) y Fraternidad y Orden y Progreso n. $^{\circ} 18$ (Oruro). En todo caso, el hecho de que la información proporcionada por el órgano de la GLP sobre los talleres en los países vecinos sea tan limitada es quizá un indicio de sus dificultades para funcionar.

El problema más urgente que afrontó la GLP en los años de la posguerra fue el de conseguir un local. Por intermedio de la logia N. ${ }^{\circ} 1$, la GLP logró que Wholey, dirigente del Gran Oriente irregular, que era el locatario de la sede ubicada en Callejón de San Francisco 27 (actualmente cuadra 1 del Jr. Amazonas, situado probablemente en el lado que hoy ocupa el Parque de la Muralla) les traspasara el contrato. En 1890 el gran maestre Ignacio La Puente propuso alquilar un nuevo local, pero se llegó a la conclusión de que era más conveniente firmar un contrato más largo del local alquilado que ya ocupaban, e invertir 1.500 soles en una refacción general, para lo que se constituyó una Junta Constructora, que procedió a satisfacción de todas las logias (excepto Kosmos N. ${ }^{\circ}$, que funcionaba desde mucho antes en otro local) según informó el mismo La Puente ${ }^{43}$ :

«La casa de la Fraternidad en el Callejón de San Francisco 27, ha quedado completamente transformada por reformas y reparaciones. Tiene dos templos elegante-

41 «Memoria leída en la sesión anual de la G. $\therefore$ L. $\therefore$ P. por el M. $\therefore$ R. Gran Maestre H. Eduardo Lavergne», RMP, 113 (31 de marzo de 1891): 55.

42 González Miranda 2004: 36. La logia peruana Fraternidad y Progreso N. ${ }^{\circ} 28$ denunció la participación de masones chilenos en las temibles Ligas Patrióticas que perpetraron violentos ataques contra instituciones y particulares peruanos nativos de esa provincia (Protesta 1919).

43 Historia 1982: 9. «Memoria leída en la sesión anual de la Gran Logia del Perú por el M. $\therefore$ R. Gran Maestre H. Ignacio La Puente», RMP, 101 (31 de marzo de 1890): 49. 
mente ornamentados y amueblados, salas para visitadores, para banquetes, para secretarías y para descanso, para la escuela nocturna que va a establecerse, para la oficina de la Gran Secretaría y otras dependencias. Además se han triplicado servicios de agua y gas, se está formando un jardín en el patio, una glorieta con su cantina en el fondo con vista al río.» ${ }^{44}$

La GLP también tuvo un órgano mensual de prensa: la Revista Masónica que se comenzó a publicar regularmente en febrero de 1882, bajo la dirección colectiva de Christian Dam, Eduardo Lavergne y J. A. Ego-Aguirre; a partir del cuarto número quedó bajo la sola responsabilidad de Lavergne hasta 1896. Se imprimió primero en la «Imprenta de F. Masías y Hno.», pero, por la disposición del gobierno de ocupación, en julio de 1882, el número 9 se debió imprimir como parte del diario «La Patria» y con el sello de la «Imprenta de La Patria», pero en setiembre del mismo año recuperó su autonomía, aunque siguió imprimiéndose en dicho taller hasta el número 18 (mayo de 1883). Del número 19 al 22 se imprimió en la imprenta «El Pueblo», hasta que a partir del número 23 (octubre de 1883) se comenzó a imprimir en la «Tipografía del Universo» del masón Carlos Prince (1836-1919) ${ }^{45}$. La revista, que luego asumió el nombre de Revista Masónica del Perú, cesó de publicarse en 1896 en que El libre pensamiento, bajo la dirección de Christian Dam, asumió el papel de órgano oficial de la GLP, con la novedad de publicarse cada semana y con avisaje comercial ${ }^{46}$. Sin embargo, sólo se mantuvo en este carácter hasta 1897 , en que, coincidiendo con la renuncia de Dam a la masonería, pasó a ser órgano de la Liga de Libre-pensadores del Perú, fundada por él. La RMP publicaba trabajos que los hermanos habían presentado en sus tenidas, artículos procedentes de otras revistas masónicas, noticias e informes oficiales de las logias. El desarrollo de la prensa masónica se vio alterado por las prohibiciones y excomuniones que afectaron a diversos órganos periodísticos por obra de la intransigencia católica. Así el obispo de Arequipa lanzó anatema contra la $R M P$, a la vez que condenaba a El Perú Ilustrado, El Callao, La Linterna, a raíz de los conflictos en que se vieron envueltos la escritora Clorinda Matto de Turner y el predicador protestante Francisco Penzotti ${ }^{47}$.

Otro puntal del esfuerzo masónico para mejorar el nivel cultural de sus miembros fue plantear desde el inicio la organización de una biblioteca que se

44 «Sección Editorial», RMP, 102 (30 de abril de 1890): 73.

45 Este tipógrafo masón también se encargó de imprimir otros textos para la GLP, por ejemplo, a inicios de 1891 se le encargó la impresión de 500 ejemplares de rituales de grados superiores (RMP, 113 [31 de marzo de 1891]: 68).

46 Posiblemente el último número de la $R M P$ fue el 171 (31 de marzo de 1896), véase «Sección oficial», El librepensamiento, 3 (4 de julio de 1896): 9.

47 «Excomuniones», RMP, 111 (31 de enero de 1891): 5. 
formó mediante donativos tanto de miembros de las logias como de «profanos» simpatizantes o amigos. La gran mayoría de textos donados son «procedimientos» y colecciones de revistas masónicas de diversas partes del mundo, seguidos por libros de historia, geografía, derecho y cuestiones económicas, técnica y ciencias. Entre los donantes figuraban, por supuesto, masones destacados como Eduardo Lavergne, Federico Ego-Aguirre, el impresor Carlos Prince, Cesáreo Chacaltana, Ignacio La Puente, pero también unos cuantos «profanos» de relieve: Manuel González Prada que obsequió La Science populaire de Claudius, una colección de divulgación científica, La astronomía, de Camille Flammarion; El Ideal de la Humanidad para la Vida, del filósofo krausista español Julián Sanz del Río, y Fuerza y materia, estudios populares de historia y filosofía naturales, del médico y filósofo materialista alemán Ludwig Büchner. Mercedes Cabello de Carbonera, cuyos hermanos Gerardo y Gustavo eran masones, obsequió sus novelas Las consecuencias y Blanca Sol, y obras de autores franceses: El noventa y tres, de Víctor Hugo; Gil Blas de Santillana, de Alain René de Lesage (versión de una novela picaresca española), y Vida de Jesús, de Renán ${ }^{48}$.

La guerra civil de 1895, en que se enfrentaron la Coalición dirigida por Nicolás de Piérola y los partidarios de Cáceres, afectó gravemente el funcionamiento de las logias, ya que diecisiete de ellas quedaron en receso, aunque la mayoría de las logias limeñas lograron continuar con su actividad. En provincias, en cambio, sólo siguieron funcionando la tacneña Constancia y Concordia N. ${ }^{\circ} 11$, la trujillana Cosmopolita N. ${ }^{\circ} 13$, la ariqueña Fraternidad Universal N. ${ }^{\circ} 20$, la Porvenir de Junín N. ${ }^{\circ} 22$ (Cerro de Pasco) y la puneña Cuna de los Incas N..$^{\circ} 24$. Prácticamente todas las logias situadas en Bolivia y Ecuador habían cesado de funcionar. Sin embargo, hacia 1896 reanudaron sus labores Orden y Libertad N..$^{\circ} 2$ (Lima), Luz del Guayas N. ${ }^{\circ} 10$ (Ecuador), Perseverancia N. ${ }^{\circ} 12$ (El Callao), Sol de los Andes N. 14 (Moquegua) y Porvenir de Huancayo $\mathrm{N}^{\circ}{ }^{\circ} 23$. Tras el enfrentamiento, se instalaron también nuevas logias en otras provincias: Porvenir de Paita N. ${ }^{\circ} 27$, Estrella del Norte N. ${ }^{\circ} 29$ (Chiclayo), Unión y Reforma N. ${ }^{\circ} 30$ (Iquitos), e incluso fuera del país: Luz de Pichincha N. 31 (Quito) en Ecuador. En suma, la implantación de la GLP corresponde a los principales centros urbanos de la república, y dentro de éstos a aquéllos de mayor desarrollo capitalista. Mayores dificultades tuvo la masonería para desarrollarse en ciudades como Cuzco o Arequipa, en las cuales, pese a

48 «Avisos. Biblioteca masónica», RMP, 111 (31 de enero de 1891): 22-24; 112 (28 de febrero de 1891): 47-48; 114 (30 de abril de 1891): 76-77; 115 (31 de mayo de 1891): 108-109. Cabe destacar este indicio de la presencia de la obra de Büchner, la cual contribuyó a la divulgación del racismo científico en el mundo de habla castellana (Sánchez Arteaga, 2007). 
los esfuerzos de los liberales y radicales locales, el clericalismo y la burguesía de cariz señorial consolidaron sus bastiones.

\section{IDEALES, PROYECTOS, PRÁCTICAS, SOCIABILIDAD}

Los masones de la GLP creían en una única divinidad (el Gran Arquitecto del Universo o G. $\therefore$ A. D. U. U.): «La Gran Logia de los Antiguos, Libres y Aceptados Masones de la República del Perú, reconoce y proclama la existencia de Dios y la inmortalidad del alma, y exige esta declaración de principios a todos sus miembros y candidatos para la iniciación ${ }^{49}$. Por esta razón se distanciaban del ateísmo, pese a su estrecha proximidad con los propugnadores del libre pensamiento ${ }^{50}$. Algunos incluso criticaron a aquéllos de sus correligionarios que, a partir de un rechazo al catolicismo, condenaban el cristianismo globalmente ${ }^{51}$. Subrayaban que la religión era una experiencia espiritual íntima en la que el poder del Estado no debía interferir y se involucraron en la lucha de diversos grupos liberales contra el artículo $4 .^{\circ}$ de la Constitución de 1860 , vigente hasta 1915 , que sólo permitía el ejercicio del culto público a la iglesia católica ${ }^{52}$. Les interesaba «la libre investigación de la verdad», razón por la cual demandaban un clima de tolerancia, requisito que el país decimonónico no ofrecía, dada la fuerte influencia de la jerarquía eclesiástica en la vida política. Asimismo, la masonería prometía un espacio de enriquecimiento intelectual y espiritual, mediado por la reflexión y la indagación en un saber secreto y ancestral preservado por la humanidad a través de los siglos, al cual no sería ajeno la ciencia. Los masones consideraban (y consideran) que el ser humano es perfectible, educable y, en suma, mejorable, pues, a su entender,

49 «Constitución de la Gran Logia de los Antiguos, Libres y Aceptados Masones de la República del Perú», RM, 4 (abril de 1882): 21; también Gran Logia del Perú, 1888: 5.

50 «El título preliminar de la Constitución de la Gr. $\cdot$ Log. $\cdot »$, por Guillermo Tell, $R M, 7$ (1. ${ }^{\circ}$ de mayo de 1882): 42. Allí se critica acremente a la masonería de Francia por admitir como masones a los que no creían en el G. $\therefore$ A. $\therefore$ D. $\therefore$ U.

51 «Material leído por H. $\cdot$ Romería en la ten. $\bullet$ ord. $\bullet$ que celebró el Tall. $\therefore$ Partenón N. 7 el 20 de mayo de 1878 , E.. V. $\therefore \gg, R M, 2$ (1. ${ }^{\circ}$ de marzo de 1882): 3-4. También existía cierta tensión con los que, como Christian Dam de la logia Orden y Libertad N. ${ }^{\circ} 2$, negaban el carácter bíblico del simbolismo masónico («Crónica», RM [28 de julio de 1882]: 1). Dam, al llegar a ser Gran Maestre en 1897, dictó un decreto desterrando la Biblia del ceremonial masónico de juramentación, sustituyéndolo por un ejemplar de las Constituciones Masónicas, medida que llevó a una crisis a la GLP que pudo ser remediada sólo con su renuncia (López Albújar, 1961: 266-276).

52 Armas Asín, 2000. 
posee una naturaleza básicamente buena sólo deformada por la ignorancia. A la influencia del dogmatismo jerárquico inspirado en la religión católica, los masones oponían los valores de la sociabilidad: patriotismo, espíritu de cuerpo, altruismo, filantropía, amistad ${ }^{53}$. Los masones asociaban la caridad hacia el prójimo con el valor cívico, antes que con un mérito para alcanzar «la salvación del alma». Sin duda, la situación del país tras la guerra con Chile ofrecía muchas ocasiones para la práctica de la caridad: hay referencias a colectas llevadas a cabo en sus tenidas (sesiones) para socorrer a viudas y familias desamparadas a raíz del conflicto ${ }^{54}$.

Fuera de su crítica general a la falta de libertad de conciencia y de cultos, y de sus creencias en la sabiduría secreta masónica, no es posible detectar un sistema ideológico unificado entre los masones peruanos. En cuanto consideraban su organización como un espacio de «búsqueda de la verdad», no se preocupaban de suscribir un único sistema de pensamiento. Los masones muestran esa «antipatía por el pensamiento sistemático» que detectaba Alfred von Martin en los sectores burgueses refractarios a la escolástica, asociada estrechamente al predominio clerical. Para escapar a esa asfixiante tutela, los masones peruanos intentaron forjar espacios de entendimiento donde lanzar ideas y proyectos que sirvieran de puntos de apoyo para su actuación en la sociedad. A través de las tenidas - exclusiva asamblea de los iniciados-y las veladas masónicas —en que se daba cabida también a los «profanos»- se buscaba crear una experiencia distinta de sociabilidad en un medio donde sólo la religión o el desfile patriótico sacaba a la gente de la reducida esfera del hogar. En esas reuniones, amenizadas a menudo con recitales poéticos y musicales, se leían y debatían trabajos sobre temas masónicos, científicos, religiosos y sociológicos, los cuales muchas veces se imprimían en la $R M P$. Una perspectiva moralizadora dominó sus concepciones de la literatura y del arte, pues consideraban que éstos debían proporcionar una sana diversión que contribuyera a la educación del ciudadano. Se tratara de la poesía o de la música, éstas debían inculcar determinados valores cívicos: la fraternidad, el amor a la ciencia, el

53 «R. . L. Perseverancia N. ${ }^{\circ} 12 »$ [Discurso por Luis Pérez Egaña], RMP, 99 (31 de enero de 1890): 6 .

54 Sobre la pobreza de Lima tras la guerra, véase: Gálvez, s.f., tomo 2: 187. Una de las primeras preocupaciones de la GLP fue organizar la junta de «Caridad Masónica»: «Las calamidades consiguientes a la situación actual han sumido en la miseria a muchas familias; y diariamente ocurren a nuestros Talleres personas menesterosas que solicitan algún socorro para mitigar sus angustias» («Memoria presentada... por el Muy Respetable Gran Maestre H. $\therefore$ Dr. D. Antonio Arenas, en la sesión trimestral de 14 de enero de $1883 », R M, 15\left[1 .^{\circ}\right.$ de febrero de 1883]: 59). 
patriotismo, un cierto panamericanismo ${ }^{55}$. Las logias que pudieron permitírselo desarrollaron la llamada «columna de la armonía», formada por aquellos hermanos que tenían capacidad de ejecutar música ${ }^{56}$. El cultivo del género lírico gozó de acusadas preferencias en la institución: Para financiar la instalación de la GLP, organizaron la presentación de la zarzuela «La Marsellesa» en el teatro Principal y en muchas veladas se interpretaron piezas operísticas. En estas actuaciones podían intervenir algunas mujeres como ejecutantes ${ }^{57}$. La presencia femenina se limitó a las veladas de las logias, pues la organización masónica sólo admitía individuos de sexo masculino y se ha mantenido así hasta nuestros días.

Los masones consideraban que el orden vigente en el Perú era negativo para el desarrollo humano. Vinculaban el atraso económico y social del país con la persistencia de la exclusividad católica en la vida religiosa, originada en la conquista y la colonización en que cristalizó «el contubernio entre la teocracia y el despotismo» ${ }^{58}$. Quizá el masón que expresó de modo más sintético esta perspectiva fue José Benigno Ugarte, quien comparaba el desarrollo técnico y democrático de Estados Unidos con las dificultades de los países suramericanos diciendo con audacia neopagana: «Poseemos más iglesias que talleres, qué digo, sólo tenemos templos para el dios de la cruz, no para el dios del arte y de la industria» ${ }^{59}$. Ugarte consideraba incluso que las dificultades organizativas de la masonería simbólica eran producto de la tradición histórica del país, sig-

55 En una exposición sobre la poesía y la música, el hermano Santiago Dávila citó elogiosamente poemas de poetas argentinos inspirados en motivos americanos: "Canto al Niágara», de Carlos Guido y Spano, «Los trópicos», de José Mármol, «Roma de los incas», de Olegario Andrade; mencionó además a José María Heredia, Rafael María Baralt, y otros poetas, y se refirió con entusiasmo a los versos patrióticos de Felipe Benavides y Valdivia, poeta chalaco. En cambio, al hablar de la música se limitó a los creadores italianos: Verdi, Bellini y Mercadante («Memoria Anual de la R. . L. O Orden y Libertad N. ${ }^{\circ}$ 2», RMP, 102 [30 de abril de 1890]: 86).

56 En este campo se destacó José Benigno Ugarte, quien, además de abogado, era compositor y director de orquesta y coros. Se encargaba de dirigir la orquesta en la apertura de las veladas masónicas, cuando ejecutaban el himno nacional. Compuso el poema sinfónico «Colón», estrenado en Lima en 1892 (Basadre, 1999?, tomo 9: 2205-2206).

57 Por ejemplo, la logia Honor y Progreso N. ${ }^{\circ} 5$ incluyó en el programa de la velada celebrada con motivo de las fiestas patrias la ejecución de la obertura de «Zampa o la novia de mármol», de Ferdinand Hérold, el gran dúo de «Un ballo in maschera», de Giuseppe Verdi (cantado por la Sra. Raquel V. de Ego-Aguirre y Alejandro Saormani, acompañados al piano por la Srta. Amelia Vargas Corbacho), el dúo de Ruy Blas de Filippo Marchetti («O dolce volutta»), y otras piezas ( «Velada literaria musical de la Logia Honor y Progreso N. ${ }^{\circ}$ 5, 28 de julio, 69. ${ }^{\circ}$ aniversario de la independencia», $R M P, 104-105$ [junio-julio, 1890]: 128-130).

58 «Sección editorial. Libertad religiosa», RMP, 111 (31 de enero de 1891): 2.

59 José B. Ugarte, «iLibertad!», RMP, 103 (31 de mayo de 1890): 101. 
nada por un régimen absolutista, la cual limitaba la implantación de un verdadero republicanismo:

«En España, en Portugal, en Italia, en Francia, y en las naciones que ayer fueron colonias de las primeras, trabajados los pueblos por el despotismo de sus gobiernos en alianza con la Iglesia, la Masonería transportada a ellos sufrió desde sus primeros días tan radical alteración, que de sociedad de hombres anhelantes de la igualdad, se convirtió en toda una corte de ridículas gerarquías, y en muchos países, formando hoy notable contraste con las instituciones democráticas que los rijen en el orden político, parece desmentir la tendencia republicana que caracteriza en esencia nuestra Institución» ${ }^{60}$.

Los masones compartían una visión de la historia universal como proceso de lucha contra el «oscurantismo», término con el cual se referían ya a la edad media, ya a las supersticiones en general, ya al fanatismo religioso. Por ejemplo, Ignacio La Puente aseguraba que la época del feudalismo había sido la más terrible de todas la épocas de la historia, por haberse asentado en la servidumbre y la prepotencia de la Iglesia, mientras veían que en el renacimiento se le presentaba una era de avance, y más todavía el siglo XVIII o de las luces. En la historia peruana exaltaban a los hombres significados por su actitud ilustrada: Toribio Rodríguez de Mendoza, sacerdote que votó por la libertad de cultos en la constitución del 1822, era visto como figura ejemplar. Entre los liberales correspondía un lugar de honor a Francisco de Paula González Vigil y, aún más, a José Gálvez, héroe de la guerra con España de 1866, cuyo nombre quedó vinculado a la institución educativa promovida por los masones ${ }^{61}$.

El interés por la ciencia - consecuencia lógica de la propensión masónica a exaltar el progreso- se plasmó en la publicación por entregas del trabajo «Primitivos seres humanos», de Antonio María Flores, ya publicado en una revista llamada Los Debates (presumiblemente extranjera) que presentaba argumentos contra la idea de creación ex nihilo (lo que actualmente se llamaría «teoría creacionista»), y concluía que la divinidad era la misma naturaleza ${ }^{62}$. En esa misma línea, se publicó «Unidad de la materia», tesis de grado de Bachiller de Margarita Práxedes Guerrero, en donde la autora, siguiendo las ideas del biólogo alemán Ernst Haeckel, desarrollaba una visión totalmente materialista y aseveraba que tanto la vida orgánica como la inorgánica tenían un solo origen (la llamada teoría monista de la materia) ${ }^{63}$.

60 «Sección editorial. La democracia en la masonería», RMP, 104-105 (junio-julio de 1890): 123.

61 «Sección editorial», RMP, 103 (31 de mayo de 1890): 97.

62 «Primitivos seres humanos», RMP, 99 (31 de enero de 1890): 21.

63 «Unidad de la materia», RMP, 111 (31 de enero de 1891): 7-10. Este trabajo fue publicado también en 1895 en El Pensamiento, revista científica que publicara la escritora argentina 
Otra disciplina que atrajo a los masones fue la psicología. En la velada organizada para celebrar la instalación de la logia «Perseverancia» N. ${ }^{\circ} 12$ del Callao, uno de sus miembros, Modesto Silva Santisteban pronunció una conferencia sobre el hipnotismo, técnica que había aplicado a varios pacientes. Poco tiempo después, quizá en un intento de equilibrar perspectivas, la revista publicó un texto crítico frente al hipnotismo del astrónomo y espiritista francés Camille Flammarion ${ }^{64}$. El uso y el abuso de la experimentación en la psicología y en la medicina en general preocupaba sobremanera al médico Ignacio La Puente, gran maestre de la GLP, quien criticó con severidad la autoexperimentación con el virus de la verruga realizada por el estudiante de medicina Daniel A. Carrión, cuya muerte, en agosto de 1885, La Puente calificó de «experiencia homicida», temiendo que redundara en el desprestigio de la profesión de médico ${ }^{65}$. Ante el público masónico, La Puente manifestó sus reservas frente a la experimentación ilimitada atribuyéndola a una psicología dominada por el materialismo científico:

«Nuestra actitud en la lucha psicológica actual debe contraerse a encerrar la escuela experimental en sus naturales límites, evitando su extravío, como ocurre, cuando con los simples datos de la experiencia pretende resolver lo que corresponde a la razón... No se crea, por esto que pretendo defender la antigua psicología escolástica... Nuestra psicología deber ser la experimental idiológica, en cuya enseñanza se han distinguido tanto los eminentes filósofos Franz y Brentano [sic] ${ }^{66}$, por parecerme la más conforme con el espíritu liberal y progresista que ha sido en todo tiempo el distintivo de nuestra sabia institución» ${ }^{67}$.

Carlota Garrido de la Peña en Santa Fé, Argentina. Allí llegó Práxedes Muñoz, procedente de Chile (Sosa de Newton, s.f.).

64 «Peligros del hipnotismo», RMP, 103 (31 de mayo de 1890): 110-112. Es posible que el medio masónico mantuviera una actitud de tolerancia hacia el espiritismo, pues el más notorio de los espiritistas peruanos, Carlos Paz Soldán, se incorporó a la GLP en 1886 (Ruiz, 1994: 69).

65 La Puente era catedrático de Química Médica en la Facultad de Medicina de San Fernando, y pertenecía a la logia Virtud y Unión N. ${ }^{\circ}$ 3; el hermano masón Ricardo Palma le dedicó su tradición «Los polvos de la condesa» que narra el descubrimiento de la quinina. El experimento de Carrión fue investigado policialmente pues se sospechó una motivación suicida en el mismo o un acto homicida por parte de los que lo secundaron (Basadre, 1999?, tomo 8: 2015; Perales, 2003). El condiscípulo de Carrión, Casimiro Medina, 2. ${ }^{\circ}$ Vigilante de la Honor y Progreso N. 5 en 1891, publicó, junto con otros, un folleto con las notas de dicho experimento títulado La verruga peruana y Daniel A. Carrión (Lima, 1886).

66 Parece tratarse de un error, ya que no son dos psicólogos distintos, sino uno solo: Franz Brentano, fundador de la psicología de la intencionalidad de la conciencia (Ferrater Mora, 1965, tomo 1: 232-233).

67 «Memoria leída en la sesión anual de la Gran Logia del Perú por el M. $\therefore$ R. G Gran Maestre H. . Ignacio La Puente», RMP, 101 (31 de marzo de 1890): 51. 
El psicologismo adquiría un cariz determinista en algunas apreciaciones de los masones sobre el entorno social en que se desenvolvían:

«comencemos la nueva era de trabajo decidido combatiendo la diátesis del indiferentismo, propia de nuestro carácter y raza y tal vez de nuestro clima y que va minando el organismo masónico nacional por su base, de una manera lenta e insensible pero infalible y decisiva y que va extinguiendo su vitalidad cual encubierta gangrena, si esta no se destruye por el fuego de la acción a cuyo calor debemos enrojecer los heroicos cauterios que con profusión o elección tiene la Francmasonería para curar las diversas llagas y podredumbres sociales» ${ }^{68}$. (cursiva de la autora.)

Sin embargo, los masones de la GLP no habían adoptado inicialmente una noción biologista de raza, sino una concepción que ponía énfasis en el grado de civilización partiendo de una igualdad fundamental incuestionable entre los seres humanos:

«La poderosa corriente de ideas democráticas... no ha podido... vencer las prevenciones que existen entre las diversas razas que componen la especie humana, prevenciones que oponen serio embarazo al desarrollo intelectual y político de los pueblos cuya población es formada de elementos diversos. En las repúblicas, en los países como el nuestro... estos desacuerdos son funestos porque ponen en peligro las instituciones liberales y detienen el desarrollo de las ideas progresistas.» ${ }^{69}$

Esta preocupación por los efectos políticos de la diversidad «racial», podía tener una deriva biologista que sobre todo apareció cuando se utilizó la noción de «raza» para promover la inmigración europea y condenar la asiática:

«No son chinos los hombres que necesitamos, sino razas superiores, cuyo cruzamiento sea un beneficio en todo sentido. Aquellos no son temibles para la Iglesia, porque siendoles la religión lo secundario y el interés lo principal, los unos sacrifican aquel a este y representan la comedia de una conversión ridícula; los más viven aislados del movimiento social, encerrados en el egoísmo característico de su raza. Mas no sucede lo mismo con los ingleses y alemanes, protestantes por lo general, que ni se prestan a ser catequizados ni por hábitos y costumbres pueden permanecer indiferentes al bien y adelanto del centro en que viven. En esto si ve ella un peligro para sus miras exclusivistas, y de allí su empeño en ahuyentarlos, presentándoles odioso el país con la amenaza de la tiranización de sus conciencias.» ${ }^{70}$

68 «R. $\therefore$ L. O Orden y Libertad N. ${ }^{\circ} 2 »$ [discurso del Venerable Maestro Castillo], RMP, 99 (31 de enero de 1890): 4-6.

69 «Razas humanas» [conferencia dada por el h. $\therefore$ Eduardo Lavergne en la R. $\therefore$ L. $\therefore$ Simb.. «Orden y Libertad» N. 2 (Publicada por orden de la logia) 9 de enero de 1882], RM, 1 (15 de febrero de 1882): 7.

70 «Sección Editorial. Libertad religiosa», RMP, 113 (31 de marzo de 1891): 49-50. 
No obstante, la ocasional percepción de la «raza» como determinante psico-biológico no dejó de coexistir entre los masones con la idea muy arraigada de que la educación laica era el medio para sacar al pueblo del «oscurantismo», producto del monopolio eclesiástico sobre la educación. Consecuentes con dicha postura procedieron a fundar la escuela nocturna «José Gálvez», que inició sus labores en junio de 1890. La escuela se dirigía a un público masculino amplio: «al obrero que quiere progresar en su ocupación», «el dependiente que quiere... salir de su círculo circunscrito», «el joven que sostiene a sus padres», pero fuera del dato de que se inscribieron 120 estudiantes, carecemos de información sobre el tipo de alumnado que efectivamente asistió a estas clases. Además de brindar conocimientos prácticos y técnicos (por ejemplo: derecho comercial, teneduría de libros, etc.) la escuela pretendía llegar «[al] hombre del pueblo, que hasta hoy por la carencia de conocimientos de sus deberes y de sus derechos políticos, ha estado reducido a servir de medio para el logro del depravado fin de demagogos y ambiciosos...». Los profesores fueron los siguientes hermanos masones: E. Lavergne, J. A. y Federico Ego-Aguirre, H. Coronel Arce Ruesta, M. Vásquez, M. Montero, I. Acuña, E. Lazarte ${ }^{71}$. Es probable que el profesorado, a la vez que impartía enseñanza académica, tratara de captar adeptos para la orden.

José Benigno Ugarte estuvo a cargo del curso «Deberes y derechos del ciudadano», muy directamente inspirado en Deberes del hombre, trabajo que el dirigente republicano y carbonario italiano Giuseppe Mazzini (1805-1872) escribió para los obreros italianos en $1860^{72}$. Ugarte cumplía así la misión masónica que la GLP se había propuesto para implantar una ciudadanía democrática republicana. Treinta años después, en Lima, Ugarte adaptó incluso el tono exhortatorio y moral de dicho escritor para dirigirse a un público de artesanos limeños:

«Yo, sin otro título que el amor hacia vosotros, artesanos, y el cumplimiento de la obligación, que mis compañeros me han impuesto, vengo a enseñaros vuestros deberes morales y políticos, y así mismo, los derechos que como a ciudadanos os corresponden... Sois la base del edificio social; sois los elementos de toda obra que engrandecerá a nuestra Nación; justo es que no seáis olvidados» ${ }^{73}$.

Ugarte consideraba que la situación de atraso intelectual y material, el descrédito, y la desgracia acarreada por motines, revueltas y «demasías de todo

71 «Crónica», RMP, 104-105 (junio-julio de 1890): 128.

72 Otros autores citados por Ugarte en menor medida fueron los teólogos católicos Jaime Balmes y Félicité de Lamennais, autor del Livre du peuple.

73 José B. Ugarte, «Deberes y Derechos del ciudadano. Curso dictado por José B. Ugarte en la "Escuela José Gálvez"», RMP, 106 (31 de agosto de 1890): 180. 
género» la debía el Perú a una categoría de hombres a los que llamaba los falsos patriotas: «los alborotadores de los pueblos, charlatanes malvados cuyo oficio consiste en incendiar las pasiones de las masas populares, para servirse de ellas en orgías salvajes de sangre y de esterminio». En cambio, los verdaderos patriotas serían «los hombres que cultivan los campos, que animan los talleres, que surcan los mares, llevando o trayendo a los diversos puntos del globo los objetos necesarios a la vida o a la inteligencia humana» ${ }^{74}$.

Aunque Ugarte siguió en casi todos los aspectos a Mazzini, existen diferencias producto del contexto así como diferencias de concepto más definitivas. Por ejemplo, mientras Mazzini propone una colaboración entre hombre y mujer, con un énfasis en la igualdad, Ugarte, si bien acepta que la mujer «no es esclava ni sierva», enfatiza que es al hombre al que corresponde la autoridad en el hogar, si bien no exclusiva pues a la madre le corresponde «el gobierno interno ${ }^{75}$. Mazzini también explicó a los obreros italianos su posición ante el comunismo, punto que Ugarte soslayó en sus lecciones, probablemente por considerarla irrelevante en la Lima de 1890. En cambio, enfatizó que la libre asociación para los ciudadanos era sagrada e inviolable, como fundamento del progreso, afirmando que «[t]odo Gobierno que osara restrinjirla haría traición a la misión social: el pueblo debería, amonestarlo primero, y luego, una vez agotadas las vías pacíficas, derribarlo» ${ }^{76}$.

Ugarte consideraba que la asociación libre y voluntaria era la alternativa a una repartición injusta de la riqueza, fundándose en la obra del economista francés André Cochut, autor de Les Associations Ouvrières, histoire et théorie des tentatives de réorganisation industrielle opérées depuis la révolution de 1848 (París, 1851) ${ }^{77}$, al abordar el problema de la formación de capital por los trabajadores. Igualmente consideraba que para asegurar el desarrollo del capital y el trabajo en el país había que expropiar los bienes de la Iglesia. Es probable que en su interés por el cooperativismo industrial se encuentre la semilla de su evolución posterior, ya que Ugarte llegó a desarrollar una clara simpatía por la organización sindicalista promovida por los primeros anarquistas perua$\operatorname{nos}^{78}$. En cuanto a la comunidad indígena, Ugarte pensaba que debían supri-

74 Ibidem: 181.

75 Ibidem: 190.

76 Ibidem, RMP, 107 (30 de setiembre de 1890): 213. Este pasaje parafrasea la formulación de Mazzini: «Si un gobierno restringiera la libertad de asociación, vosotros tendríais derecho a revolucionaros» (Mazzini, s.f.: Deberes: 130).

77 Dictionnaire, 1858: 411.

78 Años después Ugarte pronunció una conferencia pública encargada por la GLP, donde propuso el socialismo como solución pacífica de los problemas que afrontaba el país (Ugarte, 
mirse las tierras de comunidad, «para que haya en nuestros naturales vida de hombres libres, no existencia de parias, y desaparezca ese estado antagónico de los pueblos de nuestra sierra, y penetre aquí el movimiento civilizador de educación y progreso» ${ }^{79}$.

El republicanismo masónico fue vacilante en lo que respecta a la idea de incorporar a las mujeres a la vida cívica, pues, como señalaba Ugarte, consideraban que el ámbito natural de la mujer era el hogar, aunque pensaban que debían liberarla allí de la influencia de la iglesia, o más precisamente de la de los curas y religiosos, para que pudiera educar hijos con valores de tolerancia y libertad. El debate sobre el matrimonio civil - aunque tocaba algunas cuestiones relativas a la posición de las mujeres - fue ante todo abordado como un episodio de la lucha por la tolerancia religiosa. Se interesaron con vehemencia por casos puntuales en que se puso sobre el tapete la condición de las mujeres en la esfera pública. Ilustrativa al respecto es la defensa incansable que los masones hicieron en 1889 de Clorinda Matto de Turner, cuando sufrió el asedio clerical por haber permitido (en su calidad de redactora de El Perú ilustrado), la publicación del relato «Magdala» del escritor abolicionista brasileño Henrique Maximiano Coelho Neto (1864-1934), lo que la obligó a renunciar a su puesto para que pudiera seguir circulando esta publicación ${ }^{80}$. Por una parte, los masones veían a la mujer con cierto sentimentalismo: «Superior en sus sentimientos al hombre, aun cuando no lo sea en otras cualidades... en instantes supremos, posee más imajinación y hasta más energía que el hombre, por lo que es naturalmente heroica» ${ }^{81}$; por otra, los masones creían que la educación de las mujeres debía fomentarse para incluir no sólo el cultivo de las letras sino también de las ciencias: La Junta de Beneficencia de la GLP ofreció a Margarita Práxedes Muñoz el apoyo financiero para finalizar sus estudios en la Facultad de Medicina y vio en ella un ejemplo que debía ser seguido, para que, «...venciendo preocupaciones ridículas en nuestros días, buscase la muger en el ejercicio de las profesiones científicas una posición honrada e independiente

1896). Véase asimismo la semblanza «José B. Ugarte», publicada con motivo de su fallecimiento en La Protesta, 84 (1. ${ }^{a}$ quincena, enero de 1920): 1. También una biografía sintética en: Basadre, 1999?, tomo 9: 2205-2206.

79 RMP, 108 (30 de octubre de 1890), p. 239. Lo que andando el tiempo se llamaría «la cuestión indígena» no era un tema ajeno al medio masónico, pues Manuel Vázquez, masón procedente de Huánuco, leyó un trabajo titulado «Los indígenas del Perú» en la velada literario-musical organizada por la logia Orden y Libertad N. ${ }^{\circ} 2$. Aunque no se transcribió su contenido, se dice que perseguía «el fin noble de la redención del indio» («Memoria Anual de la R. $\therefore$ L. Orden y Libertad N. ${ }^{\circ} 2 », R M P, 102$ [30 de abril de 1890]: 86).

80 Mannarelli, 2002: 5. «Sección editorial», RMP, 107 (30 de setiembre de 1890): 193.

81 «La fraternidad en la mujer», $R M, 13$ (1. ${ }^{\circ}$ de diciembre de 1882): 96. 
en la sociedad $\left.\left.{ }^{82}\right\rangle\right\rangle^{83}$. Entre los masones de la GLP había conciencia de que existía en el mundo la masonería femenina; lo demuestra la publicación de los datos de la estadística masónica mundial y las referencias a la historia de la masonería femenina en Europa ${ }^{84}$. En 1896 los masones de Trujillo plantearon la necesidad de fomentarla en combinación con escuelas laicas para niñas, como medios para contrarrestar la esfera circunscrita a que la Iglesia y la sociedad reducían a las mujeres ${ }^{85}$. En la sesión anual del 29 de marzo de 1897 la GLP aprobó la creación de logias de adopción con el fin explícito de preparar a las mujeres a seguir «los consejos de sus esposos» $\mathrm{y}$ «los dictados de su conciencia» para que pudieran educar a sus hijos en la caridad, la justicia y la tolerancia. Se publicó incluso el discurso que dio Margarita Práxedes Muñoz en la logia de adopción bonaerense « 8 de marzo», donde la autora no se ocupaba tanto de la mujer en el hogar, como de proponer a las logias femeninas que lucharan contra el clericalismo estableciendo cursos públicos de ciencia para el pueblo y cursos gratuitos para las obreras «profanas» en que se enseñara una moral no fundada en la religión sino en el saber humano ${ }^{86}$. Sin embargo, la acción de la GLP en el medio nacional para alentar una forma estable de asociacionismo femenino a través de la masonería tuvo un corto aliento. Regía la GLP Christian Dam, librepensador radical, que pronto se vería obligado a dejar el cargo y optaría por retirarse de la actividad masónica completamente para dedicarse de lleno al activismo librepensador. Tras su partida, los masones de la GLP parecen haber abandonado toda preocupación por promover la masonería entre las mujeres y actualmente se niega explícitamente el ingreso a las mujeres a sus logias, aduciendo que siguen los lineamientos de la masonería inglesa... aunque la sociedad peruana es muy distinta, claro está.

82 «Gran Logia del Perú. Sesión del 8 de junio», RMP, 104-105 (junio-julio, 1890): 136. La tesis de Margarita Práxedes Muñoz fue publicada por la $R M P$, véase nota 30. Poco después viajó a Chile a estudiar, y posteriormente fue iniciada en Buenos Aires en la logia de adopción «8 de marzo».

83 «Logias de adopción», El libre pensamiento, n. ${ }^{\circ} 44$ [3 de abril de 1897], p. 171.

84 «Masonería extranjera», $R M, 9$ (28 de julio de 1882): 2. Allí se indica la existencia de más de dos millones y medio de masonas en el mundo, frente a casi 19 millones de masones. En «La fraternidad en la mujer. Lo que fue y debe ser en el siglo XIX», por Philia, $(R M, 13$ [1. ${ }^{\circ}$ de diciembre de 1882]: 96-99) se trata de la historia de la masonería femenina en Francia.

85 «Crece el escándalo» [transcripción de editorial de La Razón de Trujillo, 15 de agosto de 1896], El libre pensamiento, 13 (29 de agosto de 1896): 51.

86 «Logias de adopción», El libre pensamiento, n. ${ }^{\circ} 44$ (3 de abril de 1897): 171. 


\section{LA PRESENCIA MASÓNICA EN LA ESCENA PÚBLICA Y EN EL JUEGO POLÍTICO}

Con actos caritativos como la entrega de una suma para la construcción del hospital de Huacho por la logia local N..$^{\circ} 12$ o donaciones pecuniarias a las viudas de la guerra con Chile, los masones intentaron transmitir al público que constituían una asociación beneficiosa para la colectividad, y no un grupo pernicioso de descreídos que atentaba contra el bienestar espiritual del país, tal como la propaganda clerical repetía machaconamente. De forma más contestataria, sin embargo, los masones se empeñaron en abrir la vida pública a la libertad de conciencia, por lo cual estuvieron atentos a combatir todo lo que podía significar un rearme del campo clerical. Por esa razón, se opusieron con energía, aunque sin éxito, a la reimplantación de la Compañía de Jesús en el Perú de la posguerra, cuando las elites debilitadas por la derrota ante Chile buscaron en la educación religiosa un factor de cohesión y normalización. Los masones presionaron al gobierno organizando una Asamblea Liberal en el Teatro Politeama en septiembre de 1886, para defender la ley de 1855 que prohibía la residencia de los jesuitas en el territorio de la república. Al frente de la comisión que entregó el acta de dicha asamblea al gobierno de Cáceres, estuvieron masones como el general César Canevaro y Ricardo Palma. Sin embargo, la resolución del Congreso favorable a la ley de 1855, fue vetada por el Ejecutivo, siendo ministro de Justicia y Culto, Luis Felipe Villarán ${ }^{87}$. Mientras los sectores conservadores de la clase dominante veían en la Iglesia una base para la reconstrucción de su predominio social, los masones, junto con otros sectores burgueses liberales y radicales, sintieron que la posguerra con la atmósfera de crítica y de cuestionamiento que suscitó era el momento propicio para desprenderse de la influencia católica, lo que implicaría sobre todo asegurar, a través de una educación laica y liberal para las elites y el pueblo, una vía de modernización para el país. De ahí también la lucha para que se abrieran los cementerios a todos los ciudadanos sin excluir a los no católicos y para que se estableciera el matrimonio civil, medidas que consideraban indispensables para que el país pudiera absorber las corrientes migratorias procedentes de países europeos no católicos.

Que los estratos superiores de la sociedad no estaban dispuestos a arriesgarse a un experimento liberal lo indica la actuación de los propios masones. Aunque deseosos de tener una participación abierta en la escena pública, no era raro que tropezaran con la negativa de sus propios correligionarios. Cuan-

87 López Albújar, 1958: 61-64. Otra versión en: Klaiber, 1988: 111-112. 
do la GLP hizo preparativos para desfilar como corporación cívica en el cortejo que trasladó a la capital los restos de los que habían caído junto con Grau en la defensa del Perú, el hermano masón Dr. Ramón Ribeyro, que ocupaba la alcaldía de Lima en 1890, le negó la autorización, aduciendo que surgiría un conflicto con la autoridad religiosa por haber dado el propio gobierno un carácter religioso a la ceremonia ${ }^{88}$. Además de masón, Ribeyro era abogado y militante del Partido Civil. Se superponían en él una serie de intereses que lo llevaron a descartar el adoptar una actitud pública claramente liberal (son los años en que el civilismo aliado a Cáceres procura reconstruir su antigua relevancia). No será el único caso entre los masones y estas dobles y triples lealtades serán un factor que influirá para limitar la acción masónica. De todos modos, los masones siguieron insistiendo en sus planes de lograr una presencia pública. A propuesta de la pujante logia Honor y Progreso $\mathrm{N}^{\circ}{ }^{\circ}$, las logias iniciaron una colecta de fondos para erigir un obelisco de 21 metros de alto para homenajear a los caídos de la guerra de 1879, que sería adquirido a la firma Monumental Bronze de Bridgeport, Connecticut, en Estados Unidos ${ }^{89}$. El plan era colocar este obelisco en la plazuela de San Agustín (hoy esquina del Jr. Camaná con el Jr. Ica), pero no parece haberse realizado.

Más efectiva fue la acción de los masones en defensa de la libertad de cultos, centrada en la lucha contra el artículo $4 .^{\circ}$ de la constitución de 1860 vigente en el Perú. Momento culminante en ese proceso fue la defensa de los derechos religiosos del protestante Francisco Penzotti ${ }^{90}$. La GLP le proporcionó los abogados defensores José María Vivanco y Alberto Químper, hermanos masones. Cuando Penzotti fue liberado, la logia Honor y Progreso N. ${ }^{\circ} 5$ premió con una medalla de oro y esmaltes a Alberto Químper. En su discurso, el orador subrayó que los masones habían actuado para defender un derecho inalienable: el de la libertad de conciencia, y no para favorecer una religión en contra de otra ${ }^{91}$. Los masones seguían con atención el comportamiento de los políticos en relación con la liberalización religiosa. Así la logia N ${ }^{\circ} 5$ premió al diputado civilista, Ricardo García Rossel, representante de Lima, por haber

88 «Crónica. M. $\therefore$ R. Gran Logia del Perú», RMP, 109-110 (noviembre-diciembre de 1890): 247. El general César Canevaro, que llegó a ser gran maestre de la GLP, había sido antecesor de Ribeyro en la alcaldía de Lima.

89 Esta firma, fundada en 1879, se especializó en producir monumentos funerarios y recordatorios en zinc, llamado «bronce blanco», teóricamente más duraderos que la piedra. Tuvo gran éxito y existen numerosas muestras de su producción en los cementerios de Estados Unidos. No se conoce su difusión en otros países.

90 Basadre, 1999?, tomo 9: 2176. Armas Asín, 2000: 158-170.

91 «Crónica», RMP, 112 (28 de febrero de 1891): 25. 
defendido en el Congreso de la República «el honor, la propiedad y la vida» de Matto de Turner, agraviados durante el episodio ya referido ${ }^{92}$.

No sorprende que el activo masón José Benigno Ugarte tildara a Nicolás de Piérola de «aciago» dictador y a su dictadura de «fatídica», dada la estrecha vinculación de este personaje con el sector ultramontano. Hay indicios, en cambio, de que algunos caceristas compaginaron sus inclinaciones políticas con la masonería, tal fue el caso del general Pedro E. Muñiz, miembro de la logia Virtud y Unión N. ${ }^{\circ}$ 3, y que como tal figuraba con el cargo de primer vigilante en su cuadro de oficiales de $1891^{93}$. En igual sentido apunta la actuación del hermano masón, general Manuel Velarde (1833-1900), que había sido ministro del segundo gabinete de Cáceres (octubre-noviembre de 1886). También era miembro del Partido Constitucional y del Centro Militar y Naval, una organización de oficiales del ejército y la marina, fundada en 1888, que intentaba servir de correa de transmisión entre Cáceres y las fuerzas armadas. Velarde renunció al gabinete por desacuerdos sobre el contrato Grace con los tenedores de bonos de la deuda externa y publicó el folleto crítico Los antiguos contratos del Perú y el contrato Grace (Lima, 1887) ${ }^{94}$. Velarde había pertenecido a la logia Orden y Libertad N. ${ }^{\circ} 2$, y reanudó su actividad masónica en enero de 1890 incorporándose a la Honor y Progreso N. ${ }^{0} 5^{95}$. En la sesión del 27 de marzo de 1890, en que se realizaron las elecciones anuales de la GLP, Velarde fue prácticamente impuesto como gran maestre ${ }^{96}$. En su discurso de aceptación del cargo confesó que había estado inactivo, pero sin haber renunciado a los valores de la masonería: «Masón desde muchos años, aunque por algún tiempo separado de las logias, no he olvidado, como no olvidaré jamás, que la Franc-masonería es una escuela de moral universal... que reconoce y proclama la esencia de la individualidad humana $\rangle^{97}$. Al cierre del discurso de Velarde, el periodista Carlos Germán Amézaga, miembro de la logia Alianza y Firmeza N. ${ }^{\circ}$ 6, tomó la palabra para felicitarlo calurosamente. Además, la $R e-$ vista Masónica del Perú reproducirá en sus páginas una biografía de Velarde escrita por el citado Amézaga y publicada antes en Perú ilustrado. Allí se in-

\footnotetext{
92 «Crónica», RMP, 108 (30 de octubre de 1890): 220-221.

93 «Cuadros de oficiales de las logias de la jurisdicción para el año 1891», RMP, 110-111 (noviembre y diciembre de 1890): 266.

94 Reano, 2002: 59. Basadre, 1999?, tomo 8: 2028-2029.

95 «Sueltos», RMP, 99 (31 de enero de 1890): 1.

96 Cuando meses después se produjo la renuncia de Velarde al cargo, la $R M P$ comentó que no era necesaria a la GLP ninguna personalidad política, por muy relevante que fuera, y que siempre habría debido respetarse el voto de la mayoría. De lo que se deduce que no fue votado mayoritariamente.

97 «Sesión anual de la gran Logia del Perú», RMP, 101 (31 de marzo de 1890): 63.
} 
forma que Velarde, tras su renuncia al gabinete, aceptó la prefectura de Trujillo y luego la del Callao, a cuya población Amézaga atribuye un «inmenso júbilo» por dicho nombramiento, por lo que concluye: «El general Velarde es, pues, uno de los hombres más simpáticos que se dibujan en el escenario político... $\rangle^{98}$. Es probable que Velarde volviera al seno de la masonería en un esfuerzo por conseguir una base de apoyo a sus ambiciones en vista de las elecciones de abril de 1890, que llevaron al poder a Remigio Morales Bermúdez, militar de la órbita cacerista. Un indicio del impacto de las elecciones de 1890, controladas por Cáceres, en el mundo masónico es el hecho de que la logia Orden y Libertad N..$^{\circ} 2$ viera disminuidas sus sesiones, debido a los «trabajos electorales» que ocuparon a sus miembros.

En una sesión extraordinaria en julio de 1890, Velarde intentó que se firmara un protocolo de relaciones fraternales entre el Supremo Concejo $33 .^{\circ}$ y la Gran Logia del Perú, a lo que se opuso con toda energía el hermano Christian Dam, por considerar que vulneraba los fueros de las logias simbólicas ${ }^{99}$. Este fracaso probablemente hizo que Velarde se replanteara su papel en la GLP. Pocos meses después, en la sesión trimestral del 14 de setiembre de 1890, Velarde renunció al cargo de gran maestre de la GLP, cargo que debió ser asumido según estatutos por el diputado gran maestre, Eduardo H. Lavergne, redactor de la $R M P$ y miembro de la logia Orden y libertad N. ${ }^{\circ} 2^{100}$. En el ámbito profano, la carrera posterior de Velarde tuvo otro éxito efímero al ser nombrado ministro de gobierno y presidente del gabinete de Remigio Morales Bermúdez, manteniéndose en el puesto de marzo a mayo de 1893 (al parecer Velarde debió dimitir por diferencias sobre el nombramiento de un prefecto).

Sin embargo, ¿se podría estudiar la masonería simplemente como mera red de intercambios para obtener mayor poder, influencia y/o prestigio? La respuesta tiene una doble vertiente. En efecto, los propios masones formularon una crítica a esta concepción de la sociabilidad masónica. El gran maestre Lavergne señalaba aludiendo directamente a la elección de Velarde:

«Una de las causas del estacionarismo en la masonería, ha sido, indudablemente, que la elección de los miembros de la Gran Logia del Perú, con muy honrosas excepciones, ha recaído en algunos personajes políticos, o acaudalados, y como tales nada son, ni vigorosos, como que son víctimas de la gangrena que ha aniquilado

98 «General don Manuel Velarde», RMP, 101 (31 de marzo de 1890): 69.

99 «Michigan», RMP, 106 (31 de agosto de 1890): 174. Dam era representante de la Gran Logia de Michigan ante la GLP. Los masones desarrollaron una especie de diplomacia a través de sus logias y grandes logias. Existía también la figura del «garante de la amistad» para formalizar las relaciones entre logias distintas.

100 «Crónica», RMP, 107 (30 de septiembre de 1890): 198. 
a mi patria; y por lo mismo no han podido comunicar la savia que necesita este árbol, de tantas esperanzas para el perfeccionamiento de los peruanos.») ${ }^{101}$ (cursiva mía)

La posición de Lavergne quizá representaba la ortodoxia masónica más depurada, la cual podía compartir con otros sectores liberales y radicales una visión sumamente crítica de la sociedad, como la de aquellos masones que coincidieron con Manuel González Prada en la formación del Círculo Literario, fundado en 1886, el cual se transformó en mayo de 1891 en partido político: la Unión Nacional, cuyo programa incluyó tres puntos que habían estado presentes en las páginas de la $R M P$ : favorecer la inmigración europea, oponerse a la inmigración asiática y permitir el derecho al voto incluso a los extranjeros ${ }^{102}$. Entre los fundadores de la Unión Nacional figuraron por lo menos tres masones declarados: el ya citado Lavergne, Christian Dam y Carlos Germán Amézaga (probablemente ya enfriado su entusiasmo por Velarde). Este sector masónico, pues, tenía razones para distanciarse del cacerismo y sus representantes: la experiencia de la lucha contra la reimplantación de la compañía de Jesús en que justamente el ejecutivo había bloqueado la resolución del congreso contra dicha reimplantación les había llevado a esta desconfianza. Por otra parte, los hermanos masones afines al civilismo tampoco se habían mostrado muy decididos en su liberalismo, y, aunque no se identificaban con el clericalismo pierolista, tendieron a consentir y respaldar un proyecto elitista de educación dirigido por instituciones religiosas. De esta manera quedó establecido un marco que a largo plazo implicaría el empobrecimiento del sistema educativo en manos del estado. En ese sentido, no era equivocada la percepción de los masones más ortodoxos que creía que sólo una mayor fortaleza de las instituciones nacionales podía garantizar un espacio para una reproducción social del liberalismo.

La guerra civil de 1895 interrumpió la actividad de muchas logias hasta junio de 1896, en que fue reanudada bajo la égida de Christian Dam en el cargo de gran maestre. En términos de los intereses masónicos de dar impulso a la libertad de cultos en el país, el resultado de dicho conflicto resultaría poco favorecedor, si no abiertamente contrario, si tenemos en cuenta que sirvió para encumbrar a Piérola, que mostró su poca disposición a medidas liberales ${ }^{103}$. Dam

101 «Sesión anual de la Gran Logia del Perú», RMP, 113 (31 de marzo de 1891): 51.

102 Basadre, 1999?, tomo 8: 2108-2109. Armas Asín, 2000: 116-117. Los restantes puntos eran: la mejora de la situación de los obreros, la devolución de tierras a las comunidades indígenas, la rendición de cuentas por parte del congreso, la imposición de impuestos indirectos.

103 Bajo el gobierno de Piérola, el Congreso aprobó la implantación del matrimonio civil, aunque luego se dio un decreto que limitó sus alcances (Basadre, 1999?, tomo 9: 2324-2325). 
instó a sus hermanos masones a inscribirse en los registros de electores por medio de una circular fechada el 30 de noviembre de 1896, a fin de votar por los candidatos que la GLP recomendaría por ser defensores de las libertades. Para las elecciones de 1897, Dam llegó a un acuerdo con su partido, Unión Nacional, para que algunos masones destacados en la lucha por la libertad de pensamiento: Francisco L. Crosby, Ignacio La Puente, César Canevaro y otros, integraran las listas de candidatos. Sin embargo, Unión Nacional no respetó el acuerdo tomado vetando precisamente a estos candidatos por lo cual Dam abandonó la militancia en ese partido ${ }^{104}$.

\section{APUNTES FINALES}

El eje unificador de los masones de la GLP con los sectores liberales fue la supresión o modificación del artículo $4 .^{\circ}$ de la constitución de 1860 vigente en el Perú hasta 1915. La crisis surgida por la derrota en la guerra con Chile llevó a un sector importante de la burguesía a dar a la Iglesia un papel crucial en la reconstrucción del orden social y mental del país, mientras que los sectores liberales pugnaron por convertir esa coyuntura en una oportunidad para renovar la sociedad mediante la realización de los valores laicos del republicanismo. Los esfuerzos de los masones de la GLP por crear un ámbito asociativo que no dependiera de instancias corporativas, ya fuera el ejército, ya la iglesia o el estado, se vincularon a este replanteamiento de la sociedad, promoviendo su concepción del individuo como ente de voluntad autónoma. Sin embargo, los atisbos de igualdad que podían ofrecer en una sociedad obsesionada por el status, la jerarquía y la delimitación minuciosa de los grados de superioridad e inferioridad social no avanzaron hasta llegar al decidido fomento del asociacionismo femenino en el marco de las logias. De esta manera la GLP no procuró desmontar el confinamiento de las mujeres, y no cuestionó el orden patriarcal en el país, donde se siguió privando a las mujeres de experiencias asociativas cívicas y laicas, con lo que se dificultó el desarrollo de la ciudadanía femenina.

Para muchos individuos con ambiciones políticas el hacerse miembros de alguna logia — principalmente en la capital— los revestía del prestigio de los

104 Dam, 1897: 23-24. Fue un momento de retroceso en varios frentes para este activo masón, que se retiró entonces de la masonería (véase nota 8) para dedicar sus esfuerzos a mantener el semanario El Libre pensamiento, ya exclusivamente vinculado a la Liga de Libre-pensadores del Perú, de la que era fundador y jefe (Valdivia Acuña, 2002: 156; Zanutelli Rosas, 2005: 95-96). 
valores republicanos, fundamento mismo de la existencia de la nación, y de los cuales los masones de la GLP se consideraban depositarios. La adhesión a dichos valores, expresada en la lucha por la libertad de cultos y la tolerancia, daba pie a que éstos mantuvieran una oscilante relación con la política. El peligro que José Benigno Ugarte denunciaba en 1890 acerca de la influencia negativa del medio en la masonería, parece haberse hecho realidad en las sucesivas crisis que ésta debió afrontar a lo largo del siglo XX, al ser permeable al tráfico de influencias a la par que vulnerable a la represión contra toda expresión pública no católica, que, pese a la aprobación formal de la libertad de cultos, siguió existiendo consentida o reforzada por los gobernantes republicanos en sus intentos de lograr respetabilidad ante los círculos tradicionalistas que capitalizaban el prestigio moral en el país. La expectativa de una vida espiritual liberada del control eclesiástico tropezó así con graves dificultades a lo largo de la evolución republicana. El esfuerzo de aquellos sectores burgueses que siguieron presionando por una verdadera libertad de cultos en el país sólo alcanzaría un mayor fruto cuando, al migrar a la ciudad, hombres y mujeres procedentes de los sectores medios y populares, desprendiéndose de los marcos parroquiales que los habían constreñido, comenzaran a buscar experiencias espirituales fuera del marco del catolicismo, aventurándose a adoptar otras opciones, proceso que se prolonga hasta nuestros días.

\section{ABREVIATURAS}

GLP $=$ Gran Logia del Perú

$R M=$ Revista Masónica, órgano de la masonería simbólica del Perú

$R M P=$ Revista Masónica del Perú, órgano de la masonería simbólica del Perú

\section{BIBLIOGRAFÍA}

Armas Asín, Fernando, Liberales, protestantes y masones. Modernidad y tolerancia religiosa en el Perú del siglo XIX, Lima, Pontificia Universidad Católica del Perú y Centro de Estudios Regionales Andinos «Bartolomé de Las Casas», 2000.

Basadre, Jorge, Historia de la República del Perú, 1822-1933, 16 tomos, 8. ${ }^{a}$ edición, Lima, La República, 1999?

Beachy, Robert, «Club Culture and Social Authority. Freemasonry in Leipzig, 1741-1830», Frank Trentmann (ed.), Paradoxes of Civil Society. New Perspectives on Modern German and British History, Londres y Hamburgo, Berghahn Books, 2000: $157-175$. 
Dam, Christian, Memoria del Gran Maestre Dr. Christian Dam presentada a la M.R. Gran Logia del Perú en la sesión anual de 1897, Lima, Impr. La Industria, 1897.

De Paz Sánchez, Manuel, La masonería y la pérdida de las colonias. Estudios, Tenerife, Ediciones Idea, 2006.

Dictionnaire Universel des Contemporains, París, Librairie de L'Hachette et Cie., 1858.

Ferrater Mora, José, Diccionario de Filosofia, 2 tomos, Buenos Aires, Editorial Sudamericana, 1965,

Gálvez, José, Una Lima que se va, Obras completas, 4 tomos, Lima, Okura Editores, s.f.

Gran Logia del Perú, Constitución, estatutos, reglas de orden, antiguos linderos y antiguos cargos, Lima, Carlos Prince, 1888.

González Miranda, Sergio, El Dios Cautivo: Las ligas patrióticas en la chilenización compulsiva de Tarapacá (1910-1922), Santiago de Chile, Lom Ediciones, 2004.

Harland-Jacobs, Jessica, «Stretched even to the Ends of the Earth: Fraternalism, Imperialism and Globalization», trabajo presentado en el coloquio "Globalization, Empire, and Imperialism in Historical Perspective», The Historical Society, 2006 [http://www.bu.edu/historic/conference06.html, consultado el 9 de marzo de 2008].

Historia de la fundación de la Gran Logia del Perú de los AA. LL. y AA. $\therefore$ MM. . 1882-1982, Lima, 1982.

Klaiber, Jeffrey, S. J., La iglesia en el Perú. Su historia social desde la independencia, Lima, Universidad Católica de Lima, 1988.

López Albújar, Carlos, Masones y masonería en el Perú, Lima, Imprenta del Politécnico Nacional Jose Pardo, 1958 y 1961.

Mannarelli, María Emma, «La destrucción de las imprentas. El poder de los sexos», Libros \& Artes (julio, 2002), pp. 5-7.

Mazzini, José, Deberes del hombre, traducción de Pedro Miquel, Valencia, F. Sempere y Cía., Editores, s. f.

Perales, Alberto, «Evaluación ética de la autoexperimentación de Daniel A. Carrión y su perfil de personalidad», Anales de la Facultad de Medicina, 64/3 (Lima, 2003): 190-198.

Procedimientos de la Gran Logia de la República del Perú, Lima, Carlos Prince, Impresor y editor-librero, Calle de la Veracruz, 1887.

Protesta que formula La Muy Respetable Gran Logia de los Antiguos, Libres y Aceptados Masones del Perú, ante los Altos Poderes Masónicos del Mundo. Por los atentados cometidos por la Masonería y pueblo chileno contra los Masones y profanos peruanos en los Territorios de Tacna, Arica y Tarapacá, Lima, Imprenta «El Escritorio», 1919. 
Reano, Mariella, «The Origins of Peruvian Professional Militarism», Tesis de Grado, Maestría. Liberal Arts, Louisiana State University, 2002.

Reseña histórica de la fundación de la $R .: L .: S$. Honor y Progreso, 2005: http://es.geocities.com/lhyp5/index.htm [consultada 12/3/2008].

Romo Sánchez, Manuel, «Los Lynch en la masonería chilena del siglo XIX», Archivo Masónico, 6 (Santiago de Chile, 2005a): 29-50.

- «La masonería en Arica en el siglo XIX. Primera parte. 1863-1892», Archivo Masónico, 7 (Santiago de Chile, 2005b): 11-25.

- «La masonería en Arica en el siglo XIX. Segunda parte. 1893-1902», Archivo Masónico, 8 (Santiago de Chile, 2006): 3-40.

Ruiz Zevallos, Augusto, Psiquiatras y locos: Entre la modernización contra los Andes y el nuevo proyecto de modernidad. Perú: 1850-1930, Lima, Instituto Pasado y Presente, 1994.

Sánchez Arteaga, Juan Manuel, «La racionalidad delirante: el racismo científico en la segunda mitad del siglo XIX», Revista de la Asociación Española de Neuropsiquiatría, 27, 2 (2007): 111-126. Disponible en: http://scielo.isciii.es/scielo.php? script $=$ sci_arttext\&pid=S0211- 7352007000200011\&lng=es\&nrm=iso [consulta: 26 de marzo de 2008]

Sánchez Ferré, Pere, La maçonería a Catalunya (1868-1936), Barcelona, Edicions 62, 1990.

Solar, Alberto del, Diario de Campaña [1886], Alicante, Biblioteca Virtual Miguel de Cervantes, 2000.

Sosa de Newton, Lily, «Carlota Garrido de la Peña y su revista El Pensamiento», La máquina del tiempo [http://www.lamaquinadeltiempo.com/Mujeres/garrido/htm]. Consulta: 8 de febrero de 2008.

Torres Chávez, Claudio, «Historia de la fundadora... Parthenon n. . 4», Fénix, año 14, 27 (Lima, 2. ${ }^{\text {a }}$ quincena, abril 2006): 3 y 5.

Ugarte, José Benigno, Reforma moral y social del Perú, $1 .{ }^{a}$ conferencia popular dada por la Gran Logia del Perú en honor de la República Argentina... Lima, Imprenta Ledesma, 1896.

Valdivia Acuña, María Inés, «Masonería y librepensamiento en Lima (1884-1906)», Tesis para optar el grado de Licenciatura. Facultad de Humanidades, Universidad Federico Villarreal, 2002.

Zanutelli Rosas, Manuel, Periodistas peruanos del siglos XIX. Itinerario biográfico, Lima, Universidad de San Martín de Porres, 2005.

Fecha de recepción: 11 de junio de 2008

Fecha de aceptación: 20 de octubre de 2008

Envío versión adecuada a las normas: 12 de enero de 2009 


\section{MASONIC LIMA: SYMBOLIC LODGES AND THEIR PROGRESS IN URBAN AREAS AT THE END OF THE $19^{\text {th }}$ CENTURY}

This article deals with the organization of the Grand Lodge of Peru, founded in 1882. Using Masonic publications and sources, it aims to establish the dynamics of its local lodges and to assess the character of Masonic activity in Peru at the end of the $19^{\text {th }}$ century. Finally, it examines the political positioning of the Masonic leadership and its performance in the national political scene where it challenged Catholic exclusivity.

Key words: Liberals, Freemasons, associations, civil rights, religious freedom. 